\title{
EL “ÁNFORA CANANEA” Y LAS MEDIDAS DE CAPACIDAD EN EL ORIENTE MEDITERRÁNEO DE LA EDAD DEL BRONCE FINAL
}

\author{
THE CANAANITE JAR AND CAPACITY MEASUREMENTS IN THE \\ EASTERN MEDITERRANEAN IN THE LATE BRONZE AGE
}

\author{
por
}

JOSÉ ÁNGEl ZAMORA LÓPEZ*

RESUMEN

ABSTRACT

\begin{abstract}
En el Oriente Mediterráneo de la Edad del Bronce final se extendieron, como reflejo de un intenso comercio, cierto tipo de contenedores cerámicos de transporte y almacenamiento. Testimonios epigráficos de la misma área muestran además el uso regular y avanzado de unidades de medida. Pretendemos mostrar cómo una medida de capacidad estándar atestiguada en estos archivos remite a un contenedor cerámico, casi con seguridad anfórico, que podría identificarse con una de las formas extendidas en la época por todo el Egeo, precedente tipológico de las ánforas posteriores: la llamada "ánfora cananea". Se aprecia así, además, el alto grado de sofisticación, regularización e intensidad del comercio y la administración del Levante próximo oriental a finales del II milenio a. C., algo que no debe olvidarse al considerar la extensión posterior hacia occidente de las gentes siro-palestinas.
\end{abstract}

In the Eastern Mediterranean at the end of the Bronze Age, the use of a certain type of ceramic container for storage and transport became widespread as a result of intense trade. Epigraphic records from the area show also the standard and advanced use of units of measurement. We intend to demonstrate how a standard capacity measurement found in these records refers to a ceramic container, almost certainly in the form of an amphora, which can be identified as one of the shapes widespread throughout the Aegean at the time, and which was the typological precursor of later amphorae: the so called 'Canaanite Jar'. It can thus be noted the high level of sophistication, standardisation and intensity of trade and the administration of the Mediterranean Near East towards the end of the second millennium BC, which must be taken into consideration when analysing the later spread westwards of the Syrian-Palestinian populations.

\footnotetext{
* La investigación aquí presentada se inició, gracias a una beca de la "Residencia de Estudiantes" de Madrid, en el "Instituto de Filología" del CSIC (Madrid) y continuó, gracias a una beca de la "Academia de España" en Roma, en el "Istituto per la Civiltà Fenicia e Punica" del CNR (Roma). Una primera versión de este artículo se presentó en el II Congreso Internacional de Mundo Púnico (Cartagena, 2000; actas en prensa). La evolución de alguna de las opiniones entonces expuestas nos lleva a retomar el tema y presentar en esta sede una nueva versión.
} 
Palabras claves Mediterráneo Oriental, Próximo Oriente, Edad del Bronce Final, comercio, administración, arqueología, epigrafía, ánforas, medidas de capacidad, complejidad administrativa, desarrollo social

Key words

Eastern Mediterranean, Near East, Later Bronze Age, Trade, Administration, Archaeology, Epigraphy, Jars, Amphorae, Units of Measurement, Complex Administration, Social Development

\section{INTRODUCCIÓN: EL MEDITERRÁNEO ORIENTAL EN LA EDAD DEL BRONCE FINAL}

A finales del II milenio a. C., el Mediterráneo oriental constituía una gran zona de interacción entre ámbitos culturales muy ricos y diversos. En ella, lejos de separar, el mar unía territorios dispares mediante una intensísima red de contactos.

Las aguas mediterráneas bañaban por el sur las tierras del Egipto del Reino Nuevo. Alcanzaban, por el norte, las costas septentrionales de Anatolia, dominada entonces por el Imperio Hitita. Egipcios e hititas se repartían también el dominio de la costa siro-palestina, zona que fue además punto de encuentro con las culturas mesopotámicas del interior. Por el oeste, Creta y la Hélade, habitadas por los griegos que conocemos como Micénicos, constituían un límite más abierto, puente a su vez hacia el Mediterráneo central y occidental. Una miríada de islas facilitaba, por añadidura, los contactos marítimos. En el Mediterráneo más oriental, era la gran isla de Chipre la que adquiría un papel central, escala de numerosas rutas.

De todos lo pueblos con acceso a este puente intercultural, algunos se muestran especialmente activos como "vectores" de estos contactos. Aunque no en todo bien conocidas, de cara al mar parecen vivir las poblaciones griegas, que en el I milenio a. C. mostrarán con claridad ésta vocación marinera. Lo mismo que sucederá con las poblaciones de la costa siro-palestina que, más integradas en el complejo mundo político de la Edad del Bronce Final, nos proporcionan valiosas informaciones sobre esta época crucial.

\section{EL ORIENTE MEDITERRÁNEO Y EL ARCHIVO UGARÍTICO}

El Oriente más mediterráneo, en sentido estricto la franja costera siro-palestina, estaba poblada por gentes que, con término de origen lingüístico, llamamos semitas noroccidentales. A veces, con palabra de complejas connotaciones históricas, llamamos a estos pobladores "cananeos". Al menos una parte de ellos, ya en el I milenio a . C., fueron llamados "fenicios" por los griegos. En la época que nos ocupa, a finales del II milenio a. C., se organizaban en pequeños reinos cuyos monarcas, no siempre en buena convivencia, se sometían al gran rey de Hatti o al gran rey de Egipto. Testimonio de sus avatares políticos y reflejo de las complejas prácticas diplomáticas de la época son las conocidas tablillas del archivo de El-Amarna ${ }^{1}$, cartas intercambiadas entre los reyezuelos siro-palestinos y el faraón durante el periodo en el que la capital egipcia se situó en tal lugar.

Alguna de las ciudades de Siria-Palestina nos proporciona también información textual propia. Una de ellas, ubicada en la zona norte de la costa levantina, no lejos de Chipre y Anatolia, resulta especialmente importante. El yacimiento de Ras Shamra, la antigua Ugarit ${ }^{2}$, proporciona una muy abundante e informativa

1. Véase p. ej. la edición y traducción de Moran (1992; versión francesa, 1987); más reciente, Liverani 1998-1999. Sobre la diplomacia amarniana, también reciente, véase p. ej. Cohen - Westbrook 2000.

2. Un estado de la cuestión reciente sobre la investigación ugarítica en Watson - Wyatt 1997. Una introducción a la arqueología del lugar: Yon 1997. Un repaso a los hallazgos epigráficos, p. ej.: Pardee - Bordreuil 1992. 
documentación, tanto internacional (cartas, tratados, edictos de los reyes y virreyes hititas) como local (mitos, relatos épicos, textos rituales, registros administrativos, actas jurídicas). Junto a tablillas escritas en cuneiforme silábico y lengua acadia (forma de comunicación habitual en toda la zona), y junto a algunos testimonios menos numerosos en otras lenguas y escrituras, en Ugarit se han hallado gran número de tablillas en una escritura y en una lengua propias. Son los textos en alfabeto cuneiforme y lengua ugarítica ${ }^{3}$. Permiten conocer aspectos de la cultura de los pueblos de la costa siro-palestina a través de una documentación generada por ellos mismos en su propia lengua y con su propio sistema de escritura. Un sistema, por otra parte, ya alfabético, que muestra la perfecta funcionalidad y la ya importante extensión del uso del alfabeto a finales de la Edad del Bronce.

Del conjunto de los textos destacan por su número los registros administrativos, originados por la actividad de la administración del reino costero siro-palestino cuya capital era Ugarit. La mayoría de los textos administrativos están escritos en cuneiforme alfabético, aunque hay también un no despreciable número de ejemplares en cuneiforme silábico, reflejo de la flexibilidad de la administración ugarítica. Los textos administrativos alfabéticos recogen, entre otras interesantes informaciones, productos variados: áridos, comodiferentes tipos de cereal; líquidos, como el vino o el aceite; sólidos, como diversos metales... En la mayor parte de los textos se consignan cantidades de estos productos junto a antropónimos, nombres de grupos de personas, topónimos, etc., según la función administrativa del documento. Corresponden al registro de entregas, recepciones o inventarios de cantidades de estos bienes, reflejo de las actividades económicas que quedaban bajo el control administrativo de los diferentes archivos encontrados en la ciudad. Estas actividades, aunque permiten dibujar un cuadro de conjunto relativamente acabado, revelan en su detalle una complejidad que no debe ser enterrada en esquemas rígidos, ni perderse en interpretaciones condicionadas por ellos ( $c f$. p. ej. Zamora 1997).

Si el contenido de estos textos resulta de enorme interés, el estudio mismo del lenguaje administrativo revela ya interesantes datos. En los textos citados destaca la presencia de determinadas convenciones, parte de la sintaxis propia, específica, de los documentos administrativos.

Un caso concreto de sintaxis administrativa da pie a esta investigación: las formas de consignación de cantidades de líquidos expresadas en unidades de medida. Estudiaremos a continuación la manera en que los escribas ugaríticos registraban las actividades económicas que concernían a su trabajo administrativo y que tenían que ver con cantidades, normalmente de una cierta entidad, de productos líquidos. En especial, de aceite y vino. Como veremos, de tal estudio se deduce que la medida "estándar" de capacidad ugarítica, omnipresente en los textos, podría corresponder a un contenedor cerámico igualmente "estandarizado" y extendido, mediante el intenso comercio de la época, por todo el Mediterráneo Oriental. Pretendemos identificar tal recipiente con un tipo de ánfora característica del momento: la llamada "ánfora cananea".

\section{LA MEDIDA DE CAPACIDAD UGARÍTICA}

En los textos administrativos en lengua ugarítica, las cantidades de los productos líquidos más importantes se acompañan, en la inmensa mayoría de los casos, de la palabra ugarítica $k d$. Como pretendemos mostrar

3. Los textos ugaríticos que se presentan en el artículo se citan según el número $T U$ o $U D B$, tal y como fueron publicados, p. ej., en el GRSC (Cunchillos et al. 1996) y en las recientes ediciones del BDFSN ugarítico (Cunchillos et al. 2001a, b; 2002a, b; 2003). El número es esencialmente coincidente con la edición KTU (Dietrich - Loretz - Sanmartín 1976) y sólo en algunos casos varía respecto a CAT (Dietrich - Loretz - Sanmartín 1995). Se citarán, donde sea necesario, correspondencias y eventuales divergencias con otras ediciones y numeraciones. Las abreviaturas de revistas y series son las habituales, así como las referencias a numeraciones arqueológicas o epigráficas. 
en detalle, se trata en estos contextos, funcionalmente, de una unidad de medida. Por etimología, el término remite a una vasija, a nuestro entender, como veremos, un cántaro 0 ánfora ${ }^{4}$.

El significado etimológico de $k d$ remite, en efecto, a una vasija. Formas lingüísticas relacionadas con la palabra aparecen en todo el Levante mediterráneo en el II y I milenio a. C. Hay testimonios hebreos, fenicios y arameos. Las formas hebreas aparecen, tanto en Biblia (Cf. Koehler-Baumgartner 1967-1990: 439 "grosser Krug") como en inscripciones (cf. Hoftijzer - Jongeling 1995: 487), siendo el kad siempre un tipo de vasija ( $c f$. Delcor 1974: 233 "jarre à vin", que consideraba la palabra hebrea de origen no semítico); lo mismo sucede con los más reducidos testimonios fenicios ( $c f$. Hoftijzer - Jongeling 1995: 487; Amadasi 1987: 13-27; 1990: 17-20, que se inclina en alguna ocasión por identificar el $k d$ con un ánfora, como veremos; $c f$. también Heltzer 1989: 205, 1993:51) y con las varias formas arameas (como $k d(n)^{\prime}, k a d d \vec{a}^{3}, c f$. Koehler Baumgartner 1967-1990: 439; Hoftijzer - Jongeling 1995: 487 y ss., con referencias). Todos están emparentados entre sí y con el $k d$ ugarítico. Mejor dicho, todos son testimonios en ámbitos diversos de una misma palabra o de palabras con un mismo origen. También fuera del semítico noroccidental se encuentran vocablos relacionados. Son más que probables en acadio, donde se atestigua p. ej. kandu como contenedor vinario (cf. Von Soden 1965-81: 436 "Krug"; Oppenheim et al. 1971: 148 y ss. "a container of earthware or silver, mainly for wine"). Sin duda, se trata de préstamos, en este caso con nasal (en formas atestiguadas con posterioridad). Otras formas acadias se han puesto también en relación (Dietrich - Loretz 1969: 63 señalan el acadio kütu, $c f$. Oppenheim et al. 1971: 611 y ss. Cf. también Del Olmo - Sanmartín 1996: 210; 2003: 429-30). El caso más significativoes sin embargo el griego kádos, en latín, cadus (Aloni 1983: 43-49; Amadasi 1990: 17 y ss., con más referencias; Heltzer 1995: 96; 1989: 203, 206-207; antes, p. ej. Brown 1969: 155 y ss.). La relación del vocablo con el levante podría manifestarse incluso en algún testimonio historiográfico. Heródoto (III, 20) menciona un kádos de vino fenicio (aunque también podría tratarse de "vino de palma", pues el texto es ambiguo, como apunta p. ej. en su traducción Schrader 1986: 55, n. 111; véanse, más adelante, nuestras consideraciones sobre el carácter anfórico del recipiente).

El testimonio clásico amplía el área de uso del vocablo al ámbito no semítico, donde la palabra debió de estar presente desde época muy antigua. Aunque los testimonios léxicos son en su mayoría más tardíos, quizá ya en Chipre, en una inscripción silábica arcaica, se atestigüe un kádos de vino: wo-i-no ka-to-se = woínō kádos (Masson 1961: no. 318; la importancia lexicográfica del testimonio ha sido señalada, para el ugarítico, ya por Lipinski 1970: 83; para el griego, por Aloni 1983: 43-49; para el fenicio, por Amadasi 1990: 19; cf. también, con cautela, sobre posibles atestiguaciones en lineal A o B y chipro-silábicas, las referencias de Heltzer 1993: 50-51).

Aunque el sentido originario de los términos pudo ser genérico, todos estos testimonios remiten a un tipo de vasija, en muchas ocasiones con usos vinarios. Como otras palabras del léxico vinícola, podríamos hallarnos ante un término de cultura, un nombre probablemente extendido junto al objeto al que denomina.

En sintonía con lo dicho, en los textos no administrativos el ugarítico atestigua el uso de $k d$ como una designación normal para un recipiente, sin pretensiones metrológicas ( $c f$. apariciones en Cunchillos - Cervigón - Galán - Vita - Zamora 1996: cadenas: $k d$; Cunchillos - Vita 1995: n² 2898; cf. también Zamora 2000: $517-18$ y passim $)^{5}$. Y sin embargo, el uso mayor de la palabra $k d$ se da en los registros de la administración,

4. Cf. ánfora: "Cántaro alto y estrecho, de cuello largo, con dos asas, terminado en punta, y muy usado por los antiguos griegos y romanos. ( ... ) Medida antigua de capacidad ( ... )"; 390, cántaro: "Vasija grande de barro o metal, angosta de boca, ancha por la barriga y estrecha por el pie y por lo común con una o dos asas ( ... ) Medida de vino ( ... ) Impuesto municipal sobre el vino ( ... )"; 390, cántara: "Medida de capacidad para líquidos, que tiene ocho azumbres y equivale a 1613 centilitros aprox. [sic!]" (AA. VV. 1992: 141).

5. Hay testimonios silábicos de lo que deben ser menciones de $k d$ ( $k a d d u, k a d d \bar{u} m a)$ como vasija y no como medida. Veremos después RS 19.127, que nos permitirá vocalizar la palabra. También en el texto silábico RS 19.36 (=PRU6, 163, Nougayrol (1970): 163) lín. 2 se lee $1 \mathrm{ka}($ ?)-dú (Huehnergard 1989: 136), pudiendo ser un testimonio añadido; $c f$. Sanmartín 1990: 92. 
donde, sin duda, aparece usada como la unidad de cuenta básica para líquidos. Se atestigua el $k d$ midiendo vino $(y n)$, aceite $(\check{s} m n)$ o vinagre $(h m s)$. Algunas veces, los $k d m$ son también de miel $(n b t)$, aceitunas ( $(z t m)$ u otros productos no necesariamente líquidos (p. ej. $k d m d g m$ "dos $k d$ de orujo" en 4.284: 7, según Sanmartín 1990: 92, n. 15). En algunos de estos casos el sentido de $k d$ podría no ser metrológico. Pero este sentido es evidente, en cualquier caso, en la mayoría de los contextos ( $c f$. de nuevo Cunchillos - Cervigón - Galán - Vita Zamora 1996: cadenas: $k d$; Cunchillos - Vita 1995: $n^{\circ} 2898$ ) gracias al tipo de formulación empleada, como se verá más adelante.

La explicación más sencilla de este hecho pasa por suponer que un recipiente típico para el almacenamiento y traslado de líquidos acabó convertido en una medida estándar, perdurando la vasija materialmente en uso o manteniéndose su nombre como designación de un volumen fijo (verosímil, aunque no necesariamente, el volumen de la vasija originaria).

Esta relación entre unidades de medida y recipientes no sería, como es lógico, una peculiaridad ugarítica. En la tradición mesopotámica los productos líquidos se miden en unidades que son recipientes. En los textos de Mari (s. XVIII a. C.), donde abundan las menciones de vino, la bebida es medida en DUG (karpatu), un tipo de vasija (Finet 1974-77: 129; Oppenheim et al. 1971: 219-221, esp. 221: "The use of karpatu in Mari [ ... ] and RS [ ... ] shows that it was a container of standardized size"; $c f$. p. ej. ahora en las cartas Durand 1997: 353ss.). Los textos silábicos de Ugarit, allí donde los alfabéticos utilizan $k d$, utilizan también el logograma DUG (Huehnergard 1989: 379). El logograma pudo ser leído por los escribas ugaritas en acadio, a la manera de Mari (así lo entendía p. ej. Nougayrol 1955: 221, sub karpatu y 223 Poids et Mesures; transcribe siempre DUG como karpatu, siguiendo, como el mismo dice en otras ocasiones, "la tradición babilonia"; de nuevo véase Oppenheim et al. 1971: 219-221, compárese Dietrich - Loretz 1963: 63), pero pudo también ser directamente entendido como $k d$. En cualquier caso, la medida debía ser la misma en los textos silábicos y en los alfabéticos, pues no parece probable que los registros administrativos emplearan medidas diferentes de forma extendida y combinada. No es seguro, pues no hay ningún texto en el que DUG y $k d$ se muestren equivalentes, y los testimonios de unidades de medida en los textos silábicos de Ugarit suelen seguir las tradiciones mesopotámicas en relación no siempre clara con los términos de los textos en lengua ugarítica. Pero existen tablillas alfabéticas en ugarítico con sumas de líquidos en acadio silábico (como, en el caso del vino, el texto $4.48^{6}$ ) y textos silábicos que se completan en ugarítico (como, en el caso del aceite, $4.381^{7}$ ). No dándose distinción en el empleo de lengua y escritura, pierde sentido suponer una doble realidad tras el uso de DUG y $k d$.

En el texto silábico $R S 19.127^{8}$ aparecen varias menciones de ${ }^{\text {dug }} \mathrm{ka}$ - $d u-m a^{\text {meš }}$. Se trata, como indica el determinativo inicial, de vasijas, correspondientes a los $k d m$ de los textos alfabéticos (cf. Sivan 1984: 235; Huehnergard 1987: 136; Van Soldt 1991: 304;). Tenemos así la pronunciación del plural ugarítico de la palabra, /kaddūma/, cuyo singular sería/kaddu/ (si añadimos la doble /d/que atestiguan, p. ej., las formas sufijadas hebreas). En $R S 19.127$ no parece que la palabra haga función de unidad de medida junto a una cantidad de otro producto. El texto parece anotar, más bien, las vasijas mismas (ya Nougayrol 1970: 112-113). No es posible por tanto agrupar este testimonio con los metrológicos administrativos, identificando todas las vasijas con las originarias o habituales en el uso metrológico. Pero tampoco parece necesaria tal agrupación,

6. 4.48 presenta en acadio silábico la cantidad total de vino, en DUG. Sin embargo el texto ugarítico no muestra la palabra $k d$. El caso es idéntico a 4.93. Véase también 4.381.

7. $R S$ 18.102=DO 4823=PRU 5, 34 (Virolleaud 1965: $\mathrm{n}^{\circ} 34$ ). Se trata de un texto que lista cantidades de aceite (İmes) en su anverso, medidas en DUG. Las cantidades son 20,19,5, 15, 5, 5, 5, 60, 11,80 y 5, entre las lín. 1 y 12. En el reverso se anotan, en ugarítico, cifras seguidas de un individuo, introducido por $~ l l$, "a cuenta de". Las cantidades legibles, tras un inicio muy fragmentario, son (lín. 16-23) 19, 5, 15, 5, 5, 5 y 10. Salvo la última, coinciden todas, 6 de 7, con cantidades del anverso, al que deben completar o referirse. Uno y otro registro se relacionan.

8. DO 513=PRU 6, 147 (Nougayrol 1970: 147; foto Schaeffer et al. (1962): 128, fig. 109). Se encontró en el "Palacio sur". Véase también supra $\mathrm{n} .5$. 
pudiéndose diferenciar el uso del $k d$ en el grueso de los textos administrativos de un uso diverso, más propiamente material y no metrológico, típico de los textos "literarios" y de algunos textos cotidianos.

La medida administrativa puede traducirse igualmente como "vasija", de forma genérica, ya sea como recuerdo del origen de la unidad o como presunción de un uso real de vasijas. Como defenderemos más adelante con otros argumentos, dado el tipo de "vasija" que, en cualquier caso, se relaciona con los usos del $k d$, proponemos traducir la palabra como "ánfora". Los testimonios lingüísticos comparativos parecen ir, también, a favor de esta traducción. Todos remiten a recipientes, en muchas ocasiones cerámicos y de cierto tamaño. Algunos, remiten a tipologías más concretas: se dan casos en los que tanto el kados griego como el $k d$ fenicio parecen referirse, propiamente, a ánforas ( $c f$. Amadasi 1990: 19, con referencias; nótese de nuevo su vinculación al vino).

\section{EL KD ADMINISTRATIVO}

La clave del estudio de la naturaleza metrológica del $k d$ son los textos administrativos ugaríticos. Los testimonios son muchos. Sin embargo, a pesar de la abundancia de menciones de cantidades de vino y aceite (cf. p. ej. Cunchillos - Cervigón - Galán - Vita - Zamora 1996: cadenas: yn, šmn; Cunchillos - Vita 1995: $\mathrm{n}^{\circ} 2540,5499$ ), la presencia de la palabra $k d$ o $k d m$ ("ánfora", "ánforas") es mucho menos numerosa de lo que podría esperarse ( $c f$. igualmente Cunchillos - Cervigón - Galán - Vita -Zamora 1996: cadenas: $k d, k d m$; Cunchillos - Vita 1995: $\mathrm{n}^{\circ} 2898$ y 1084, n²907). Esto es debido a la forma en que las cantidades de líquido son anotadas. Veamos un ejemplo:

En el texto $4.285^{9}$ aparecen consignados individuos con cantidades de vino. Observese que internamente el texto no manifiesta si se registra, por ejemplo, una entrega o una recepción:

\begin{tabular}{|c|c|c|}
\hline 1 & {$[\ldots \underline{t} l] \underline{t} \cdot \dot{y} n$} & [ ... tr]es (ánforas) de vino. \\
\hline 2 & {$[\ldots a]^{\circ} b^{\varsigma} \cdot y n$} & [ ... cua]tro (ánforas) de vino. \\
\hline 3 & {$[\ldots t] \tilde{s}^{\circ} \cdot y n$} & [ ... nu]eve (ánforas) de vino. \\
\hline 4 & {$[\ldots] \stackrel{d}{d} \cdot \underline{t} m n \cdot y n$} & —d: ocho (ánforas) de vino. \\
\hline 5 & {$[i] y \underline{t} r . k d m \cdot y n$} & [I]ytr: dos ánforas de vino. \\
\hline 6 & $\stackrel{\bullet}{s} d y n \cdot a r b^{c} \cdot y n$ & $\check{S} d y n$ : cuatro (ánforas) de vino. \\
\hline 7 & $a b s ̌ k n . k d m \cdot y n$ & Abškn: dos ánforas de vino. \\
\hline $7 \mathrm{a}$ & & \\
\hline 8 & $\breve{s b n} \cdot k d m \cdot y n$ & Šbn: dos ánforas de vino. \\
\hline 9 & 'bdilm.țmn.y & 'bdilm: ocho (ánforas) de vino. \\
\hline \multicolumn{3}{|c|}{ marg. inf. } \\
\hline 10 & $q s ̣ n \cdot \not \grave{m}[\check{s} \cdot y n]$ & $Q s \underline{n}$ : cin[co (ánforas) de vino]. \\
\hline 11 & $a r n y \cdot b[m \check{s} \cdot y n]$ & Arny: ci[nco (ánforas) de vino]. \\
\hline $11 \mathrm{a}$ & & \\
\hline \multicolumn{3}{|c|}{ rev. } \\
\hline 12 & ağltn . bms̆[ $[y n]$ & Aǵltn: cinco[ (ánforas) de vino \\
\hline
\end{tabular}

9. $R S$ 17.287=PRU 2, 85 (Virolleaud 1957: $\mathrm{n}^{\circ} 85$ ) $=D O 4645$. Encontrada en el Palacio Real, hab. 56. 
Hay 12 individuos con sus correspondientes cantidades de vino. Estas cantidades son anotadas mediante el numeral y la palabra yn, "vino". Solamente en lín. 5, 7, 8 aparece la unidad de medida, bajo la forma $k d m$. En los casos en que aparece la unidad de medida, no aparece el numeral. Esta es la norma básica. La palabra $k d$ se elide o presupone en las listas administrativas, sobreentendida por la mención de "vino", yn, que sucede a la cifra. Tan sólo reaparece funcionando como un numeral, al que sustituye. En singular, $k d$, equivale a la unidad. La presencia de $k d m$, que morfológicamente podría entenderse como un plural, es en realidad un equivalente del numeral "dos" mediante el uso del dual: "dos ánforas" ( $c f$. ya Hoftijzer 1971, 361-364) ${ }^{10}$. Es decir, un ánfora de vino se consigna $k d y n$; dos ánforas de vino: kdm yn; tres ánforas de vino: tlt yn; cuatro ánforas de vino: $a r b^{<} y n ; \mathrm{y}$ así hasta la decena.

El uso del singular de la unidad de medida con valor 1 y del dual con valor 2 es un hecho bien conocido que se da también con otras medidas, como el siclo, $\underline{t} q l$. Incluye la formación de numerales compuestos (ya Wesselius 1980: 448-450) ${ }^{11}$. En tal contexto aparece también la palabra $k b d$, típica de las listas ugaríticas con numerales. En los numerales compuestos funciona como signo de suma entre las diversas cantidades en las que se descompone el numeral, esencialmente (aunque no sólo) entre las decenas y las unidades, así ordenadas. P. ej., en 4.213:4-5, $a r b^{\complement} m$. hmšs. kbdyn debe entenderse "cuarenta y cinco (ánforas) de vino" "12. Como numeral compuesto, puede incorporar las formas singular o dual de $k d$, p. ej. $4.213: 2, t \breve{s}^{c} m . k d m . k b d$. yn, "noventa y dos ánforas de vino".

La función de $k b d$ en los textos ugaríticos ha sido muy discutida, y todavía es objeto de estudio. La primera significación que se le atribuyó, "pesado", como calificativo de un tipo especial de siclo o de otra unidad de medida, no se sostiene. Se da en contextos donde el siclo no aparece, ni tendría sentido que apareciera. Suponiendo otras unidades de medida ligeras y pesadas muchos textos son todavía más difíciles de entender. Además, no hay testimonios directos de un sistema metrológico pesado y otro ligero en los textos de Ugarit ${ }^{13}$. Hasta hace poco tiempo la propuesta más aceptada era la de Liverani (1970, 89-108), que entendía $k b d$ como un indicador de "conjunto", "suma total". Bordreuil (1985: 89-92) propuso una etimología en tal sentido ( $k$ "como" $+b$ "en" $+y d$ "mano", "como en la mano", "todo junto"). Sin embargo, existía ya otra palabra ugarítica con un significado y función muy próximos al que quería entenderse para $k b d$ : tgmr. En ocasiones, ambas palabras se daban juntas, lo que ponía en duda la exactitud de la traducción de Liverani, aunque no su crítica al significado "pesado". Del Olmo y Sanmartín (1996: 208; 2003: 425-26) solucionaban los problemas interpretativos por un doble uso de $k b d$ : como indicador de suma ("más") y como indicador de "cantidad o precio total, número justo, exacto". Tropper (1997: 661-663) ha defendido recientemente el uso general de $k b d$ como indicador de suma, "más", proporcionando una posible etimología (por una base semítica $\sqrt{ } k p t / k b t$, con el significado básico "zusammenfügen"). Al margen de ésta, del estudio de los textos administrativos surge una perfecta confirmación de sus opiniones: el uso de $k b d$ como sumador en los

10. Véase también Wesselius (1980: 448-450), con paradigma similar al nuestro.

11. Para el siclo cita 4.139: 10, $\underline{t} q \mathrm{l}$ kbd ‘̌rm, "siclo más veinte”, es decir, 21 siclos; 4.341: 1, tqqm kbd ‘šrt, "dos siclos más diez", igual a 12 siclos. J. W. Wesselius pensaba que el sistema de connotación administrativa era también muy parecido en el caso de las medidas de superficie. Estudió 4.282, texto recientemente revisado por Tropper - Vita 1998: 686-688. Véase ahora, sobre el particular, Zamora 2000: 55-76.

12. El texto fue tratado por M. Liverani (1970: 92) para delimitar el valor de $k b d$, sin acertar con el sentido exacto pero acabando con otras interpretaciones mucho más alejadas. Véase a continuación.

13. A pesar de ello, véase todavía Sivan 1997: $89, \breve{s} b^{`} k b d$ "seven heavy (shekels)". Los estudios metrológicos con base arqueológica, y no únicamente textual, son complejos. Véase p. ej. (con anterioridad al trabajo textual de M. Liverani y por tanto a la negación del $k b d$ "pesado") Arnaud 1967: 151-169. Con otro enfoque, véase p. ej. Parise 1984: 125-138. Sobre la complejidad metrológica de la zona levantina sí hay muestras en los textos de Ugarit: véase p. ej. Liverani 1972: 193-198. 
numerales compuestos, equivalente a las formas con $l$. Aunque el uso de $k b d$ es, a pesar de todo, rico y variado, no deben existir dudas sobre este valor de $k b d$ y sobre este tipo de formulaciones numéricas, que explica perfectamente la sintaxis de la mayor parte de los textos administrativos donde aparece. La palabra es un elemento habitual en la formación de numerales compuestos, un "elemento sumatorio", parte de una variante de consignación de cifras perfectamente reglada.

En el citado $4.285, k b d$ no aparece, pues todas las cifras conservadas son inferiores a la decena. La información suministrada da un total legible de 57 ánforas ${ }^{14}$.

Como resumen, puede elaborarse una tabla que, con testimonios reales de diferentes tablillas, muestra la forma en que numerales, unidades de medida y elementos sumatorios se combinan para formar las citas de cantidades de un producto, en este caso, el vino, medido en $k d$ :

\begin{tabular}{|c|c|c|}
\hline 4.246: 4 & $k d y n$ & un ánfora de vino \\
\hline 4.285: 7 & $k d m y n$ & dos ánforas de vino \\
\hline 4.285: 1 & tlt $\underline{y}$ yn & tres (ánforas) de vino \\
\hline 4.285: 2 & $a r b^{\prime} y n$ & cuatro (ánforas) de vino \\
\hline 4.285: 11 & $b m s \check{y} y n$ & cinco (ánforas) de vino \\
\hline 4.285: 9 & $t m n y n$ & ocho (ánforas) de vino \\
\hline 4.285: 3 & $t s^{c} y n$ & nueve (ánforas) de vino \\
\hline 1.91: 21 & $\breve{s} r y n$ & diez (ánforas) de vino \\
\hline 1.91: 1 & 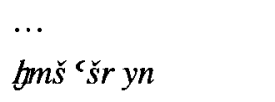 & quince (ánforas) de vino \\
\hline 4.213: 14 & 'rm yn & veinte (ánforas) de vino \\
\hline $1.91: 3$ & $a r b^{\top} m y n$ & cuarenta (ánforas) de vino \\
\hline & $\cdots$ & \\
\hline $4.213: 4-5$ & $a r b^{\complement} m b m s \check{k b d} y n$ & cuarenta y cinco (ánforas) de vino \\
\hline 4.213: 2 & $\begin{array}{l}\cdots \\
t \check{s}^{c} m \boldsymbol{k d m} k \mathrm{kbd} y n\end{array}$ & noventa y dos ánforas de vino \\
\hline & $\ldots$ & \\
\hline $1.91: 6$ & mit $\check{c}_{s} \underline{\mathrm{kbd}} y n$ & ciento diez (ánforas) de vino \\
\hline
\end{tabular}

14. Que es probablemente el total consignado originalmente, habida cuenta el espacio necesario para los antropónimos perdidos en el extremo superior izquierdo de la tablilla. Véase Virolleaud 1957: 110. 


\section{LOS SELLOS, LAS ETIQUETAS Y EL $K D$}

Otro tipo de documentación epigráfica administrativa se relaciona directamente con las ánforas: los sellos y etiquetas que se añadían a ellas o las marcas, inscripciones o pinturas que se hacían directamente sobre el recipiente. Las inscripciones y pinturas sobre los tapones, cuerpos o asas de las vasijas se dan en todo el Próximo Oriente, pero de forma desigual. En Egipto se sellaban las ánforas desde el Reino Antiguo, e incluso antes ( $c f$. Poo 1995: 5 y ss.; véase a continuación). Del Reino Nuevo, la época que coincide con el esplendor ugarítico, son famosos los ejemplos hallados en la tumba de Tutankhamon (Lesko 1995: 222; también Grace 1956: fig. IX).

En Ugarit, como en otros yacimientos próximo-orientales, se han hallado "etiquetas", pequeñas piezas de barro con informaciones escuetas, frecuentemente con marcas de sello, que se unían a bienes controlados por la administración o, muy importante, a documentos generados por ella ${ }^{15}$. Una etiqueta ugarítica, $6.11^{16}$, pudo estar unida a un recipiente vinícola, al que alude. No se trata de un tapón de arcilla sellado, sino de una etiqueta propiamente administrativa. Es pequeña, de forma troncocónica, y posee improntas de sellos (con jeroglíficos hititas) y agujeros para ser atada, quizás a un ánfora (Schaeffer 1934: 123, fig. 8a, 134; Herdner 1963: $\mathrm{n}^{\circ} 159$, fig. 232 y pl. 74; corresponde a la $\mathrm{n}^{\circ} 3$ de Van Soldt 1989: 376; se halló en la quinta campaña, en la llamada "acrópolis", cerca de la tumba V, $c f$. Bordreuil -Pardee 1989: 38). En la inscripción se lee $k \stackrel{d}{d}[$. ] y $n$ l prt., "Un ánfora de vino para Prt aluda a la cantidad de vino, exactamente un $k d$, de la vasija a la que se unía (y siempre que la etiqueta no fuera unida a otra documentación). Existen otras etiquetas similares. Hay un justo equivalente en silábico, que vuelve a mostrarnos la flexibilidad de los escribas ugaríticos en el uso de diferentes lenguas y escrituras. Se trata de $R S 15.154$, una etiqueta troncocónica, sellada y con una perforación para ser atada, probablemente a un recipiente (aunque se halló en contexto escribal ${ }^{17}$ ). En dos líneas, se lee: 1 DUG GEŠTIN $s[a(?)]^{1} a-z i-r a-[n a]$, "Un ánfora de vino de 'Ādirā[nu]", mostrando también el correlato silábico al $k d$ alfabético: DUG.

Con otra ordenación, una etiqueta, RS 22.30, anota más de un DUG: ${ }^{1} k u r$-wa-na 2 DUG GEŠTIN, "(Para ${ }^{18}$ ) Kurwānu ${ }^{19}, 2$ ánforas de vino”. Pudo estar ligada a un recipiente que contenía dos DUG, aunque de nuevo cabe la posibilidad de un uso administrativo diferente del etiquetado de ánforas ${ }^{20}:$ Se encontró en la llamada "Casa de las grandes vasijas" ("Maison aux jarres" o "Maison aux grandes jarres") donde, aunque es difícil poner en contacto los elementos arqueológicos y epigráficos conservados, se advierte la convivencia de los documentos jurídicos, los registros administrativos y las etiquetas, con una indudable relación, reflejo de un funcionamiento administrativo complejo ( $c f$. Zamora 2000: 331-333).

15. Sobre las "etiquetas" ugaríticas y el $k d$, en relación con la administración del vino, véase Zamora 2000: 328 y ss. En general, sobre las etiquetas ugaríticas, véase Schaeffer 1934: 118; Virolleaud 1957: XL ó 163-175, 187-188 (sobre las etiquetas de cestas que reúnen tablillas); véase finalmente el estudio de Van Soldt 1989: 375-388.

16. KTU 6.11=UT 59=CTA 159=RS 5.262=AO 28.064. Véase foto en Herdner 1963: pl. LXXIV.

17. Se halló en el palacio real, en los archivos este (hab. 53). Cf. Nougayrol (1955): 187 (PRU 3, 187). Es la $n^{\circ} 12 \mathrm{de}$ Van Soldt 1989: 377 , que restituye sin dudas el antropónimo.

18. "The genitive Kurwãna suggests the omission of a preposition or $\check{s} a$ ", Van Soldt 1989: 381, n. 36. Se apoyaba en otra etiqueta, donde se da expresión con el mismo individuo, ša ${ }^{\prime} k u r$-wa-na. La elisión de preposiciones, como es sabido, es común en la sintaxis administrativa.

19. En el "catastro" de terrenos 4.282: 7-9 se menciona un šir. ̌s . krm de Krwn. En el acta de transferencia de propiedad RS 15.145 una extensión de propiedad con viña pasa a Kurwanu, hijo de Ba'alazki. Pero, naturalmente, no hay forma de identificar con seguridad un único individuo bajo los diferentes homógrafos.

20. Es troncocónica, está sellada y lleva perforaciones para ser atada. Encontrada en la acrópolis sur. Es la $n^{\circ} 40$ de Van Soldt 1989: 381, del que tomamos la lectura. 
Existen otras etiquetas que pudieron también referirse a ánforas ${ }^{21}$, aunque son testimonios más dudosos ${ }^{22}$. Alguna otra etiqueta podría ser un tapón, aunque de nuevo no es seguro ${ }^{23}$. En cualquier caso, los documentos conservados en los archivos palaciales muestran la perfecta relación entre las cantidades medidas en $k d$ de los textos administrativos y los recipientes que debieron contener tales cantidades ${ }^{24}$.

También existen inscripciones en alfabeto ugarítico sobre vasijas. Se trata de testimonios escasos y muy heterogéneos ${ }^{25}$. Aunque las inscripciones conservadas no responden a la clase de hecho administrativo del que hablamos, muestran costumbres epigráficas de control ${ }^{26}$. Es de notar que en ánforas halladas en diferentes lugares del Egeo aparecen signos o letras, tanto pintadas como incisas (antes y después de la cocción), que relacionan de nuevo a Ugarit con el resto del área y llaman la atención sobre un tipo especial de recipiente extendido por toda la zona: el "ánfora cananea" ${ }^{27}$, que estudiaremos en la parte final de este trabajo.

\section{LA CAPACIDAD DEL $K D$ : TESTIMONIOS TEXTUALES Y ARQUEOLÓGICOS}

Pero ¿qué tipo de vasijas podían corresponder a estas medidas? Para empezar, ¿a qué volumen, siquiera aproximado, equivale este $k d$ presente en los textos ugaríticos? Para establecer la capacidad del $k d$, pueden utilizarse las fuentes textuales y las arqueológicas, incluidas las del entorno donde, como veíamos, el intenso contacto y el comercio regular habían extendido formas materiales y rasgos ideológicos iguales o similares.

21. 6.18, que se encontró en la misma sala que la etiqueta $R S 15.154$ (la habitación 53 del palacio real, dentro de los llamados “archivos este” -p.t. 72,73, prof. 0’70-; véase Bordreuil-Pardee 1989,83) presenta en la lín. 2 una palabra incompleta que podría restituirse [ $k] d m$, "ánforas". El contenido no se explicita, como en otras etiquetas. Debió ser evidente. En algunos casos, es la cantidad la omitida, por idénticas razones. En cambio, el nombre propio (el beneficiario, el aportador) rara vez está ausente. Véase Van Soldt 1989: 386 y ss.

22. Es posible que la restitución $k d m$ en 6.18 no sea correcta, y se trate, por ejemplo, de una cita de [d]dm, medida de áridos. Se acompaña de un número alto (lín. 1, "veinticinco"), por lo que no se trata de una simple etiqueta de ánfora. Pudiera ser, de nuevo, un indicador administrativo, una etiqueta de otros registros. Nótese como la información contextual, "metalingüística", suprime la mención del producto y por tanto cambia la sintaxis propia de otros documentos administrativos. Dietrich- Loretz Sanmartín 1995: 502, leen [d/k]dmm, sugiriendo corregir la $m$ final. En 6.18 las ¿ánforas? quedan en manos de/a cargo de 'Ubēnu.

23. P. ej. $R S$ 19.163, el n 37 de Van Soldt 1989: 381.

24. Y las etiquetas, por supuesto, prueban la existencia de prácticas administrativas de control. Un control de almacenamiento y distribución cercano a los mismos objetos controlados. Las etiquetas prueban también, por tanto, la existencia de un personal encargado de inspeccionar, contar, organizar, etc. el movimiento de las ánforas controladas por la administración, desde la base. Remitimos de nuevo a Zamora 2000: cap. IV.

25. Sobre asas de vasija se escriben $6.2,6.67$ (en un pithos), 6.70 (en una jarra) y 6.76. Sobre una vasija micénica está pintado 6.64. También 1.77 se halla sobre el asa de una gran vasija. Otras inscripciones inéditas deben corresponder también a textos sobre vasijas (p. ej., Dietrich - Loretz - Sanmartín 1995: 596 recoge como KTU 9.413 una inscripción de dos líneas sobre un asa; véase también Bordreuil - Pardee 1989: 338).

26. Así, son abundantes en Ugarit los signos inscritos antes de la cocción, véase p. ej. Courtois 1978: 278-279 («Ceramiques cananeennes à signes inscrits avant cuisson (Bronze Récent)»; ya diferentes tipos de grafitti en Schaeffer 1949b: 228). La mayor parte de signos se dan en las asas. Han aparecido incluso inscripciones cuneiformes (véase nota siguiente; p. ej. 6.76 apareció en el centro de la ciudad, véase Yon - Lombard - Renisio 1987: 82; véase en la misma obra signos sobre ánforas cananeas por todas partes, p. ej. 20, 41, 46-47, 83).

27. P. ej., en Chipre, se han encontrado con signos chipro-minoicos, y con signos llamados por el arqueólogo «cananeos», pintados o incisos en el cuerpo del ánfora, véase Åström 1991: 150. Algunas ánforas de Hala Sultan Tekke "were imported from Ugarit and Cilicia" (mismo lugar, aunque la base analítica de la afirmación es después puesta en duda). P. Åström cita también otro tipo de recipientes, como "a silver bowl with a Canaanite cuneiform inscription was found in a wall in building C" (p. 151). Se refiere sin duda a $6.67(K T U 6.68=\mathrm{N} 1450)$, véase Åström-Masson 1982: 72-77. Sobre la extensión de estas inscripciones cuneiformes alfabéticas sobre recipientes, recuérdese también, p. ej., la inscripción sobre el asa de una vasija en Kāmid el-Lōz (6.2). 
De los textos administrativos ugaríticos se deduce que el $k d$ no es una unidad pequeña. Basta con observar las listas de cantidades consignadas junto a topónimos. El número de $k d$ es a veces muy bajo, existiendo consignaciones de uno o dos $k d$. De hallarnos ante una medida de escasa capacidad, tanto si se trata de inventarios como de transacciones, las cantidades resultarían demasiado bajas. La entrega a la administración por parte de toda una aldea del equivalente a uno o dos "vasos" o "jarrillos" de vino podría considerarse poco menos que una acción simbólica o testimonial, lo que no tiene sentido dentro de esta clase de textos. Tampoco si se trata de un reparto. Como dato adicional, la cantidad de plata a pagar por un ánfora (2/7 de siclo en el texto 4.219) sugiere un recipiente grande ${ }^{28}$.

Fuera de estas reflexiones, la capacidad exacta del $k d$ ugarítico no se extrae de los textos de Ugarit, pues tampoco las listas léxicas de unidades de medida pueden arrojar más luz. Sin embargo, desde el comienzo se han asumido ciertos valores para la medida ugarítica estándar. Así por ejemplo, Virolleaud hablaba de una capacidad de unos 8 ó 12 litros por unidad de medida, dependiendo de si se trataba de una medida normal o "pesada" (Virolleaud 1940: 133) ${ }^{29}$, sin hacer más referencia a sus fuentes. En realidad, tales atribuciones no tienen base textual.

La información epigráfica es siempre difícil de manejar en cuestiones metrológicas. Muchas veces, la relación entre unidades y subunidades origina apoyos débiles, casi cruzados. Las deducciones numéricas se prestan a muchos excesos y errores de apreciación. La pervivencia de términos no asegura la continuidad de las cifras. A todo esto se añade que los datos entre diferentes archivos son difíciles de comparar, tanto más cuanto que cada archivo carga con sus propios problemas de estudio. Un buen ejemplo nos lo da Mari (ciudad también Siria y vinícola, pero interior y con testimonios textuales anteriores en medio milenio a los ugaríticos). Allí, se había deducido una capacidad de unos 10 litros para la unidad básica karpatu ${ }^{30}$, dato que resultaría interesante si no se hubieran rechazado, recientemente (Powell 1989-90: 457-517, esp. 499-500; 1995: 110), las cifras obtenidas desde los textos por la ambiguiedad de éstos ${ }^{31}$. En general, los problemas metrológicos son grandes para cualquier archivo documenta ${ }^{32}$, por lo que tampoco puede confiarse enteramente en la comparación con otras fuentes textuales.

A la luz de lo expuesto, no parece quedar más posibilidad que acudir a la arqueología y combinar su información con los textos. La vía arqueológica, en principio, se justifica bien en Ugarit, pues, al hilo de lo dicho, parece posible que la medida estándar coincidiera con un recipiente estándar ${ }^{33}$. Mucho más dado el uso y etimología de la palabra ugarítica $k d$. Aunque, como también veíamos, no es una afirmación evidente,

28. Véase, en detalle, Zamora 2000: 490. Aunque las relaciones de precios no son fáciles de evaluar (véanse referencias en el lugar citado, p. ej. Vargyas 1986: 103-116), el precio del vino con un $k d$ pequeño parece excesivo. Por ejemplo, hay textos en los que una oveja parece costar un siclo, que equivaldría a $3 k d$ y medio de vino, véase Virolleaud 1965: 124-126, $\mathrm{n}^{\circ} 101$ (PRU 5, 101). Incluso con todos los problemas apuntados, un $k d$ de poca capacidad resulta poco convincente.

29. Aparte de la confusión entonces existente con el valor de $k b d$, entendía que la equivalencia DUG = karpatu se extendía al ugarítico $k r p n$, no al $k d$ (p. 129, n. 4). En 133 distinguía las dos clases de $k r p n$, basándose en 4.48 (RS 10.45).

30. 1 karpatu = $10 q u$, cada qu de aprox. 1 litro; cf. Bottéro 1957: 351; Birot 1960: 250; Finet 1974-77: 129; Durand 1983: 192; Gates 1988: 71; Milano 1989: n. 126; Heltzer 1990: 127. Véase también Von Soden 1965-81:449-450; Oppenheim et al. 1971:219-221.

31. Powell cree que los 10 litros sugeridos crean problemas con los datos de precios. En el lugar citado, defiende que el karpatu de Mari tenía una capacidad mucho mayor, del orden de los 30 litros, aunque también podría rondar los 241 . Sin embargo, sus cifras parecen exageradas. La arqueología se encuentra con grandes problemas en yacimientos excavados desde hace tiempo. El tamaño estándar de las ánforas de Mari no ha podido establecerse arqueológicamente, véase Zettler - Miller 1995: 130-131.

32. P. ej. en el caso asirio, en el s. VIII a. C., con gran cantidad de documentación textual y arqueológica, existen aún problemas, véase Stronach 1995: 179-180 (que recoge para esta documentación: $q a=1$ litro aprox.; 10 qa = sutu; 10 sutu = 1 homer, por tanto 100 litros).

33. Recuérdese Oppenheim et al. 1971: 221: "The use of karpatu in Mari [ ... ] and RS [ ... ] shows that it was a container of standardized size". 
al menos sí parece razonable que el $k d$ equivaliera a la capacidad de un tipo de recipiente extendido. Como karpatu, el $k d$ sería el contenedor por antonomasia ${ }^{34}$.

Sin embargo, los datos disponibles sobre la capacidad de las ánforas halladas en la ciudad son pocos y discutidos. El testimonio más interesante lo constituye un grupo de ánforas halladas en Minet el-Beida, cerca del Tell de Ras Shamra, que nos ocupará más adelante. Pero incluso para este testimonio excepcional se dan cifras confusas. Según M. Liverani (1979, col. 1332-1333), la capacidad media de las ánforas era de unos 22-23 litros, cantidad que ya creía poder igualar al valor del $k d$. Sin embargo Milano (1981: 117 , n. 127), citando información directa de Courtois, arqueólogo de la misión francesa, daba una media para las ánforas de unos 10 litros, haciendo notar, además, que las ánforas más grandes variaban entre 12 y 20 litros.

El investigador que prestó más atención al asunto fue M. Heltzer (1989: 195-208; 1990: 127; también p. ej. 1987 (=1996): 106-120, esp. 109 ó 1994:318-321; 1993: 49-54; recientemente, 1999: 448). Para superar la escasez e inseguridad de los datos ugaríticos, intentó combinar las mediciones de diferentes yacimientos del entorno donde podría haberse extendido un estándar de medida ( $c f$. p. ej. Heltzer 1989: 205; 1993: 50, esp. n. 15) ${ }^{35}$. Agrupó las cifras de capacidad de las que disponía en valores cercanos a los 22 litros o a divisores y múltiplos de tal cifra. Después, acudió a los textos ugaríticos. Según Heltzer, atestiguarían también subunidades en los textos ${ }^{36}$. El sistema habría pervivido en el I milenio a. C., atestiguándose entre fenicios y hebreos ${ }^{37}$. Alrededor de 22 litros tenían también las ánforas grecorromanas ${ }^{38}$. El $k d$, según Heltzer, sería más o menos igual a 22 litros, cantidad que coincidía con la proporcionada por Liverani y que se tomó como prácticamente probada.

Sin embargo, seguía sin haber pruebas precisas. Aunque, con indudable acierto, Heltzer no se circunscribió exclusivamente al material ugarítico, consideró y seleccionó datos difícilmente comparables, uniendo testimonios muy heterogéneos, sobre todo tipológica y cronológicamente. No tomó ningún tipo concreto de recipiente como guía, asumiendo implícitamente cierta estandarización en todo el conjunto cerámico

34. Por añadidura, podría señalarse que no se han hallado recipientes-patrón para efectuar medidas. Sin embargo, incluso aceptando que la falta de testimonios no se deba al azar de la conservación o a problemas de identificación, cualquier hipótesis sugerida por ello debe ser formulada con cautela. Lo mismo cabe decir del uso metrológico directo de recipientes como los conservados: aunque al tratarse de un recipiente de cierta capacidad, cuya fabricación no exigía grandes precisiones, la desviación por encima o por debajo de la cantidad "estándar", frente al contenido total, pudo no ser significativa (y la cuenta en $k d$ podría haberse realizado, por tanto, con la cuenta directa de recipientes), la precisión habitual de los textos con las cantidades anotadas y el control estricto de la administración sobre la producción consignada no sintoniza bien con este tipo de cuentas. Nótese, sin embargo, que el vino se mide en los tex tos casi exclusivamente en $k d$, sin apenas menciones a posibles múltiplos o submúltiplos, con la inmensa mayoría de cantidades suponiendo un número exacto de $k d$.

35. Al respecto de los estándares, véase también la discusión presentada por M. C. Amouretti en Amouretti - Brun 1993:574-575, con sugerencias a favor de la extensión de un patrón mediterráneo de F. Salviat y en contra de H. Blitzer.

36. Definía también M. Heltzer una segunda unidad de medida aparecida en los textos, el $l t h$, como un décimo del $k d$. Partía de los textos 4.782 y 4.778 (RIH 84/8 y 83/12), donde aparece mlth (Heltzer 1989: 195-197; 1993: 49-54). Sin embargo, como puede ya deducirse del elenco textual, los testimonios son mínimos y dudosos, como ocurre también con otras posibles medidas (cf. Zamora 2000: 356).

37. H. Forbes propuso la relación de este tamaño de ánforas con el transporte en asno o burro. Las acémilas no podrían transportar más de dos ánforas, ni más de 60 o $65 \mathrm{~kg}$. Dos ánforas de 22 litros podrían pesar llenas más o menos esos kilos, aunque el imeru o el homer, que aluden justamente a la carga de un asno, pesan algo más. Pero el ánfora es un mal recipiente para el transporte terrestre, para el que debió preferirse el odre. Véase intervenciones de H. Forbes, M. Heltzer y A. Tchernia en Amouretti - Brun 1993: $574-575$.

38. Las ánforas clásicas, naturalmente, son variadas en forma y tamaño según época y lugar. Según Heltzer (1993: 50-51), un tipo extendido podía pesar unos $10 \mathrm{~kg}$. en vacío y contener unos 20-25 litros de vino. La capacidad es válida para muchas ánforas greco latinas, aunque no es hasta época romana que determinadas tipologías se imponen. El peso podía oscilar entre los $25 \mathrm{~kg}$ de una Dressel 1 a los $12 \mathrm{~kg}$ de alguna Dressel 2-4. El "ánfora" romana, como medida de capacidad, equivalía a unos 26 litros. Cf. Koehler 1995: 323-337 (y n. 28 sobre problemas metrológicos). Por mediciones de ejemplares de amphorae vinariae Dressel 1A y 1B (los tipos antiguos más comunes) se ha calculado una capacidad de entre 17 y 27 litros, una media de 22 litros. Las Dressel 2-4 arrojan una media de algo más de 25 litros. Véase Tchernia 1986; Unwin 1991: 364 ("Historic wine mesures"). 
considerado. Tampoco hizo distinciones cronológicas, en una época, como veremos, en la que la forma y capacidad de los recipientes, incluso la de aquellos morfológicamente más definidos, varía apreciablemente en el tiempo.

A ello debían añadirse los problemas de fondo: las medidas fiables eran pocas e irregulares; las cifras se prestaban a relaciones de cálculo muchas veces casuales; y la selección bienintencionada del material relevante, riesgo siempre presente, parecía en este caso estar fuertemente condicionada por la hipótesis previa de la continuidad metrológica entre las culturas levantinas del II milenio y las del I a. C. (continuidad confirmada por los testimonios hebreos y extendida, en último término, al mundo greco-latino).

Así las cosas, a nuestro juicio, la mejor forma de salvar las dificultades que presenta el cruce del material epigráfico y arqueológico pasa por acometer este último de modo selectivo: identificar primero el posible recipiente concreto con el que puede igualarse el $k d$, individuar la forma cerámica candidata, por uso y extensión, a ser igualada a la medida, para sólo después, y secundariamente, intentar establecer su capacidad. Como decíamos, el uso estandarizado de un recipiente de este tipo debió de extenderlo más allá de círculos como los atestiguados en Ugarit, algo quizás confirmado por los testimonios lingüísticos relativos al $k d$. Los testimonios arqueológicos deberían ampliarse con ello, proporcionando más datos y haciéndolos más fiables.

\section{LAS ÁNFORAS DE LA EDAD DEL BRONCE}

En la edad del Bronce final se daban ya por supuesto verdaderas ánforas (como veremos con más detalle; entre tanto, $c f$. Leonard 1995: 233-254). De fondo apuntado, como sus sucesoras, las ánforas podían clavarse en la arena, apoyarse unas en otras, semienterrarse en los suelos de las bodegas o encajarse en diferentes soportes de piedra, madera o metal. Para el envasado de vino, la forma pudo revelarse adecuada para el precipitado de los posos y la resistencia a las presiones de la fermentación. Resultaba, además, práctica para el transporte. El fondo resiste bien los golpes y funciona como una tercera asa en el manejo. Las formas más comunes, ni muy grandes ni muy pequeñas, podían ser acarreadas por un hombre. Un animal podía cargar varias. Pero, sobre todo, las ánforas resultaban adecuadas para el transporte en barco, el más barato en la antigüedad y probable motivo del éxito del contenedor ${ }^{39}$. Las vasijas eran muy valoradas y frecuentemente se reutilizaban ${ }^{40}$. Ánforas típicas de la época son abundantes en Ugarit. Un depósito de 80 ánforas perfectamente alineadas se encontró en un almacén o bodega del puerto de la ciudad [Fig. 1] ${ }^{41}$. Es el lugar llamado en los textos mi/ahd, Ma' hadu, "el puerto" (el actual Minet el-Beida; $c f$. Schaeffer 1932: 2-3, lám. III, 3; 1939 : 30-32, lám. IX; 1949: lám. 31; Courtois 1979: col. 1285. Sobre las excavaciones de Minet y los almacenes, véase también Schaeffer 1933: 93-127; 1935: 168 y ss. -nótese 171 la referencia a la vasija inscrita antes de la cocción-y demás informes de excavación en los números de Syria 10-16 (1929-35). Añádase ahora

39. Además de las representaciones egipcias de barcos que descargan ánforas, los pecios de la Edad del Bronce, como veremos, proporcionan ejemplares llenos de múltiples productos. El ánfora típica, por cierto, es la llamada "ánfora cananea", véase más adelante. El uso extendidísimo de ánforas para el transporte marítimo en época clásica (véase ya en la Odisea II, 349-351) tiene. por tanto gran antigüedad.

40. Seguro en Egipto, también para usos menos convencionales que el original; $c f$. Lesko 1995: 225-226 (compárese el uso de ánforas cananeas reutilizadas para la extracción de agua del Nilo con el empleo del kad bíblico, recipiente también vinario, para extraer agua de los pozos, véase Amadasi 1990: 19, con referencias). Lesko ha dedicado abundantes trabajos al tema, sobre todo desde su King Tut's Wine Cellar (Lesko 1977), en el que adelantaba algunas de sus líneas de investigación futuras. En las contribuciones del autor citadas se hallarán más referencias. Sobre las vasijas vinarias en Egipto, véase también Helck 1986: col. $1182-1186$.

41. Schaeffer 1949b: lám. 31. También en Lesko 1995: 238. Desde diferente ángulo, otra fotografía en Schaeffer 1939: pl. IX "Entrepôt de plus de 80 jarres d'un commerçant en huile ou en vin (Quartier du port d'Ugarit à Minet-el-Beida, XVe-XIVe siècle)". Ahora Marchegay 2001: 19 y 38 fotos. 
Marchegay 2001, justo a tal efecto -véase esp. 19. Sobre el topónimo alfabético mi bd/mabd-gentilicios mi bdy $(m)$, mabdy $(m)$, silábico uru $m a-a-b a-d i$, ${ }^{\text {uru }} \mathrm{KAR}^{\mathrm{ki}}$, uru $\mathrm{KAR}, \mathrm{KAR}-, c f$. Cunchillos - Vita 1995: nos. 3314-3316, 3329-3330; Van Soldt 1996: 675-676; Dietrich - Loretz 2000).

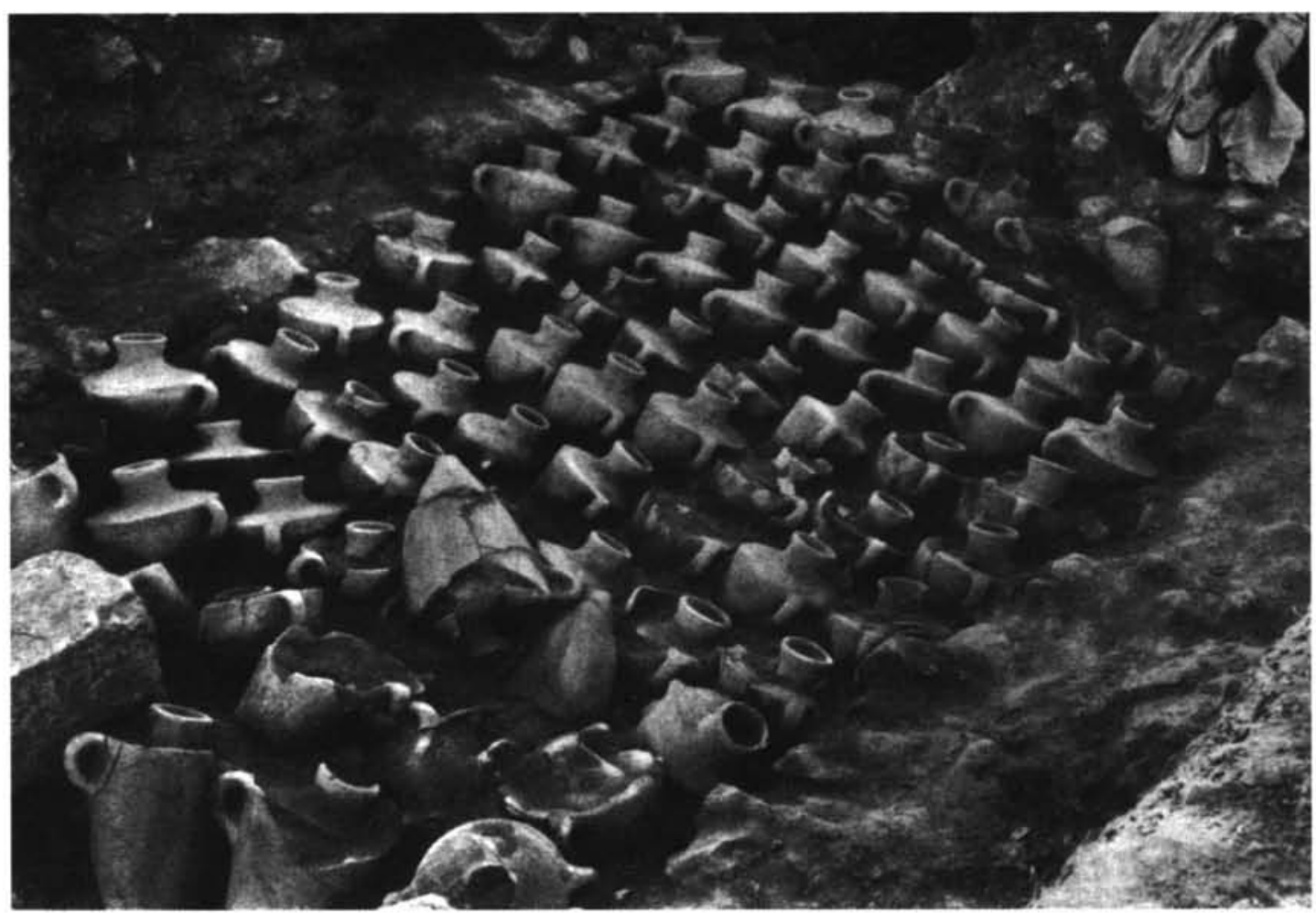

Fig. 1: Ánforas “cananeas” en un almacén del puerto de Ugarit

En Ugarit, las ánforas que aparecieron in situ en el puerto se hallaban de pie, ligeramente inclinadas, apoyadas unas con otras. Es la imagen típica de una bodega o almacén de ánforas en el II milenio a. C., muy similar a los representados en las pinturas egipcias [Fig. $2^{42}$ ].

No es de extrañar que las ánforas de Minet el-Beida hayan sido tomadas en más de una ocasión como base de estudio metrológico: se acumulan abundantes en un depósito del puerto, como una imagen viva de las cantidades citadas en los textos; son regulares y abundantes, lo que encaja perfectamente con la introducción de un uso metrológico; muchas se encontraron, además, en perfecto estado de conservación. Y pertenecen a una variedad tipológica extendida por todo el Mediterráneo oriental de la época: el "ánfora cananea".

42. Grace 1956: 87, fig. 4, 99-100. En la figura se aprecia como las ánforas de la fila inferior se apoyan en el suelo y entre sí; las de la fila superior, apoyadas en soporte, están cerradas y selladas, salvo las primeras por la izquierda, que todavía desprenden gases de fermentación. Probablemente, se muestra el proceso: fermentación con el ánfora abierta, cierre progresivo (quizá con perforación en el tapón), sellado definitivo y almacenaje ( $c f$. el citado artículo de Grace). El contexto es de vendimia. En la parte superior del detalle se hallan vides creciendo sobre columnas. Sobre la producción y administración del vino en la época, $c f$. de nuevo Zamora 2000, cap. II y IV. 


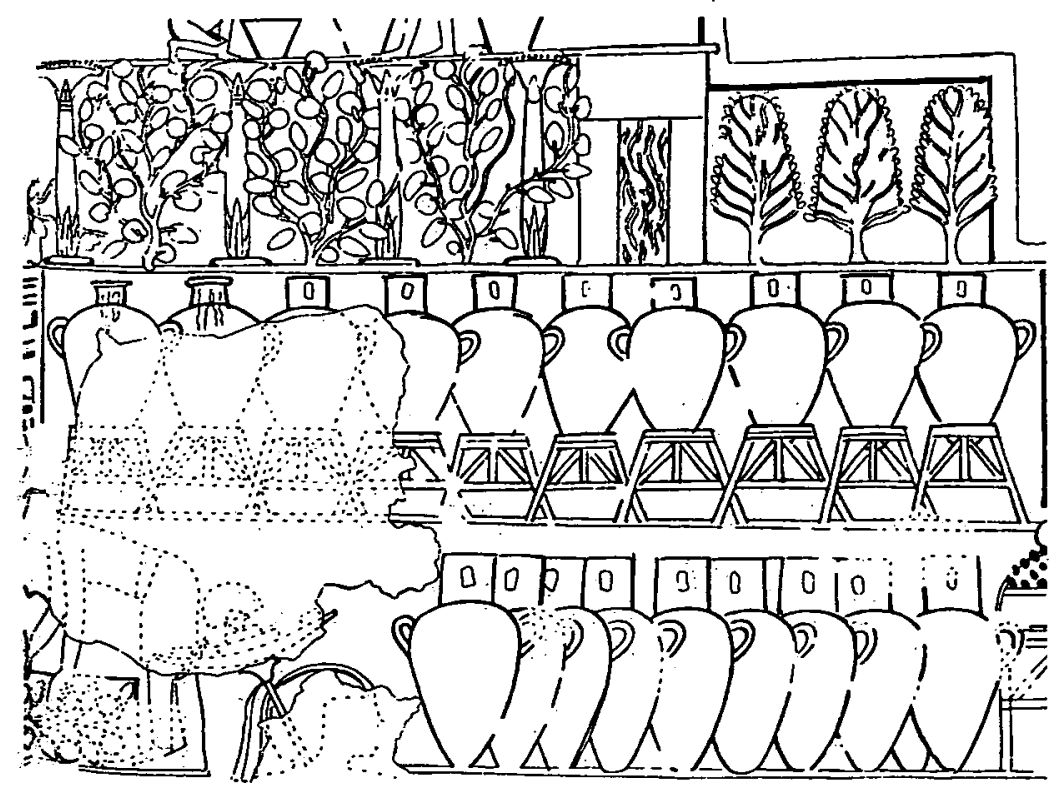

Fig. 2: Dibujo (detalle) extraído de las pinturas de la tumba de Nebamun (finales del XV-principios XIV a. C.)

\section{EL “ÁNFORA CANANEA"}

Se llama "ánfora" o "vasija cananea" (canaanite jar) a un contenedor cerámico de gran capacidad, de fondo apuntado, panza amplia y cuello estrecho, con dos grandes asas por debajo de los hombros, destinado al transporte y almacenamiento de diferentes productos, ante todo aceite y vino. Es típico tanto de Ugarit como del entorno (el área levantina y todas las costas egeas). Es precedente, por tipología y uso, de las ánforas griegas o romanas, y por supuesto de las fenicias y púnicas posteriores ( $c f$. Grace 1956: 80 y passim; véase p.ej. 96, donde se relaciona la forma con los ejemplares de la península ibérica). Se conoce como canaanite jar por su extensión por todo el Mediterráneo oriental durante la segunda mitad del II milenio a. C., con centro en las costas sirias y palestinas ${ }^{43}$. Aunque se echan de menos más estudios y análisis que fijen variantes y capacidades, así como el lugar de fabricación de los ejemplares, se reconoce una tipología genérica y algunos datos significativos [Fig. $3-4^{44}$ y $5^{45}$ ].

43. El nombre nace en el estudio antes citado de Grace 1956: 80-109. Junto a "canaanite Jars" otros nombres dados por los arqueólogos son "syrian jars", "commercial jars", "canaanite commercial jars", "storage jars", "levantine storage jars" o "conical jars", aunque parece que, convencionalmente, el primero es preferible. Véase Åström 1991: 149.

44. Ejemplar de la izda. en cata 8. IV. P. t. 43; el de la dcha., cata 7. IV. P. t. 109, a $1 \mathrm{~m}$ de profundidad. C. A. F. Schaeffer la fechaba en el Ugarit Reciente 2, según su terminología. Las fechas (1450-1365 a. C.) parecen hoy ligeramente altas (compárense con tabla adyacente; de la misma opinión, Grace 1956: 92, n. 22). Véase Schaeffer 1949b: 208-209. En Schaeffer 1939: lám. IX, 30-32, fechaba también el hallazgo en los s. XV-XIV. Ahora Marchegay 2001: 19 da detalles que confirman la mayor antigüedad del depósito frente a las últimas construcciones de la época en el lugar del hallazgo (y datos sobre la identificación del ejemplar completo conservado en el Louvre; $c f$. ya Yon 1997: 152-153).

45. Leonard 1995: 237, 240; véase también Grace 1956: lám. IX-XII, esp. X. Véase, sobre la evolución de la vasija, esp. 88 y ss. Nótese la angulación característica de los hombros del ánfora en los ejemplares más recientes. 

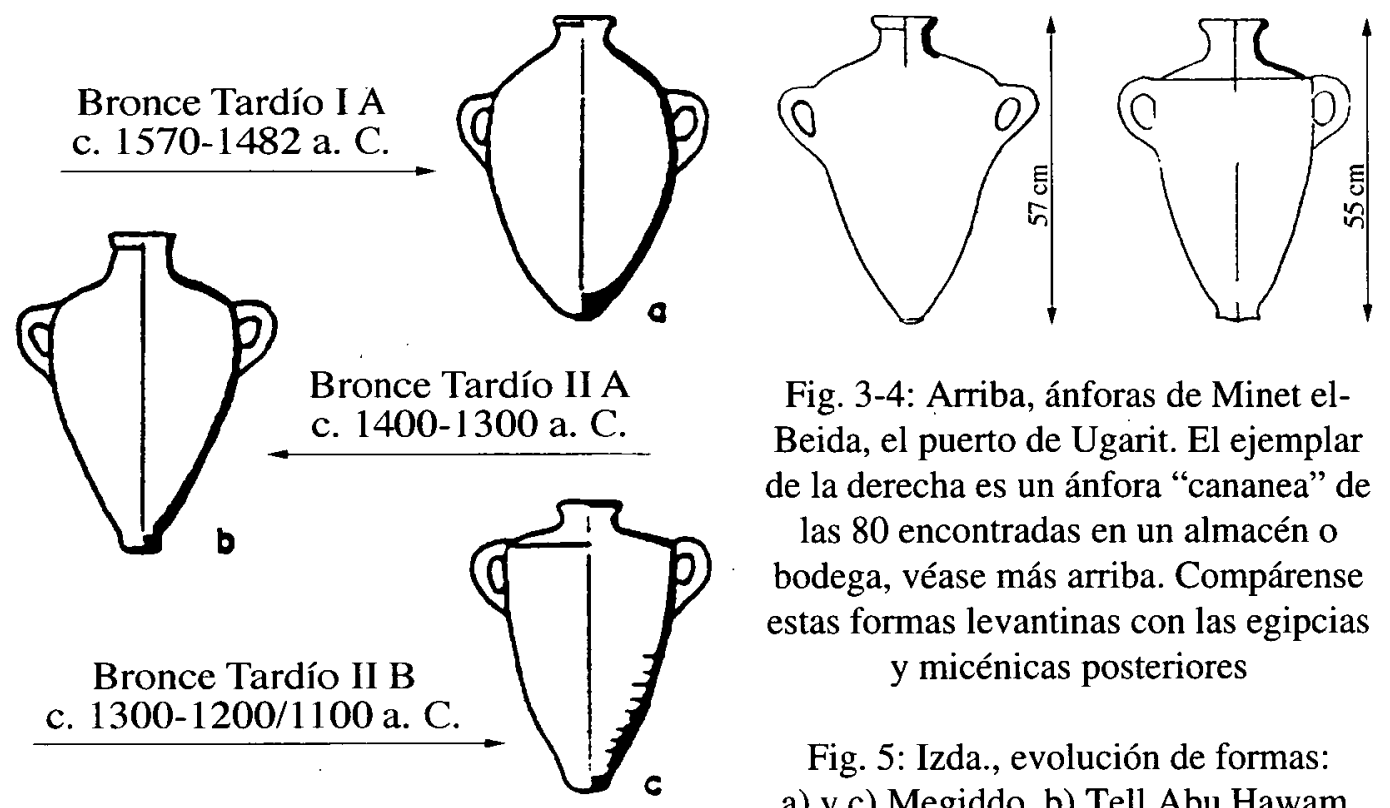

Fig. 3-4: Arriba, ánforas de Minet elBeida, el puerto de Ugarit. El ejemplar de la derecha es un ánfora "cananea" de las 80 encontradas en un almacén o bodega, véase más arriba. Compárense estas formas levantinas con las egipcias y micénicas posteriores

Fig. 5: Izda., evolución de formas: a) y c) Megiddo, b) Tell Abu Hawam.

El origen de las primeras ánforas parece ser el Levante mediterráneo ${ }^{46}$. La creación, o al menos su popularización, debe relacionarse con el vino, a principios del Bronce Medio. El tipo se extiende abundantemente en la región, en donde, con ligeros cambios, pervive durante siglos ( $c f$. Grace 1956: 83 y ss.) Las ánforas se usaban para transportar casi cualquier tipo de producto ${ }^{47}$. Por efecto del comercio con Egipto, se atestigua en el valle del Nilo, tanto en el registro arqueológico como en pinturas. Preexistían formas egipcias similares, pero la aceptación del nuevo recipiente fue muy amplia, hasta llegar a fabricarse (Leonard 1995: 239; Koehler 1995: 334, n. 6; Grace 1995: 82 y ss. -que destaca la novedad de las asas; Helck 1986: col. 1182-1186-con lámina de diferentes modelos de Weinkrüge egipcios; 1185 , se destaca también la novedad de las asas de las vasijas importadas de Siria en el reino nuevo). Las pinturas de las tumbas muestran a asiáticos portando las ánforas como tributo o bien comercial, y en escenas de vendimia se pintan grandes cantidades de ánforas. En las representaciones egipcias se aprecia el tapado y sellado que recubre y alarga el cuello de la vasija, aun así reconocible. También se aprecian los diferentes soportes que las mantenían de pie. Los hallazgos arqueológicos proporcionan los modelos reales de las pinturas. En toda la costa siro-palestina y en el Egeo hasta Micenas se han hallado ánforas en buen estado. Toda el área griega, incluida Creta, presenta ejemplares, tanto en centros palaciales como en necrópolis micénicas [Fig. 6 y $7^{48}$ ]. En Chipre, los fragmentos de "ánforas cananeas" son muy numerosos. El mayor número corresponde a los primeros años del s. XII a. C., esto es, la última etapa ugarítica. Algunas de las ánforas muestran epigrafía semítica noroccidental y, analíticamente, se ha fijado su procedencia en Ugarit y Cilicia. Aunque tal procedencia exacta ha sido puesta en duda, es innegable el origen levantino de muchas de las vasijas. Otras ánforas cananeas halladas en Chipre provienen

46. El estudio clásico de Grace 1956: 86 apostaba por un origen en Canaán, desde donde se extenderían por todo el Egeo. Después, con más cautela, igualmente Amiran 1969: esp. 140-141; véase también Leonard 1995: 233-254.

47. Como lo prueban directamente los pecios citados a continuación y nombran algunas fuentes (véanse referencias en notas anteriores; véase también Grace 1956: 98-99). Aunque no siempre es fácil de identificar, el vino parece ser un contenido típico. Asumida la vinculación al vino del ánfora, se ha llegado a afirmar que el vino levantino era muy popular en algunos asentamientos donde las ánforas aparecen en gran número, véase Åström 1991: 151 . En detalle, remitimos siempre a Zamora 2000: p. ej. 475-484.

48. Ambas figuras de Leonard 1995: 237, 240. 
de Egipto (como demuestran sellos de faraones del Reino Nuevo). También hay ánforas cananeas en los pecios de cabo Gelidonya o Uluburun [Fig. $8^{49}$, fiel reflejo del modo en el que estas ánforas se movían por toda el área ${ }^{50}$.
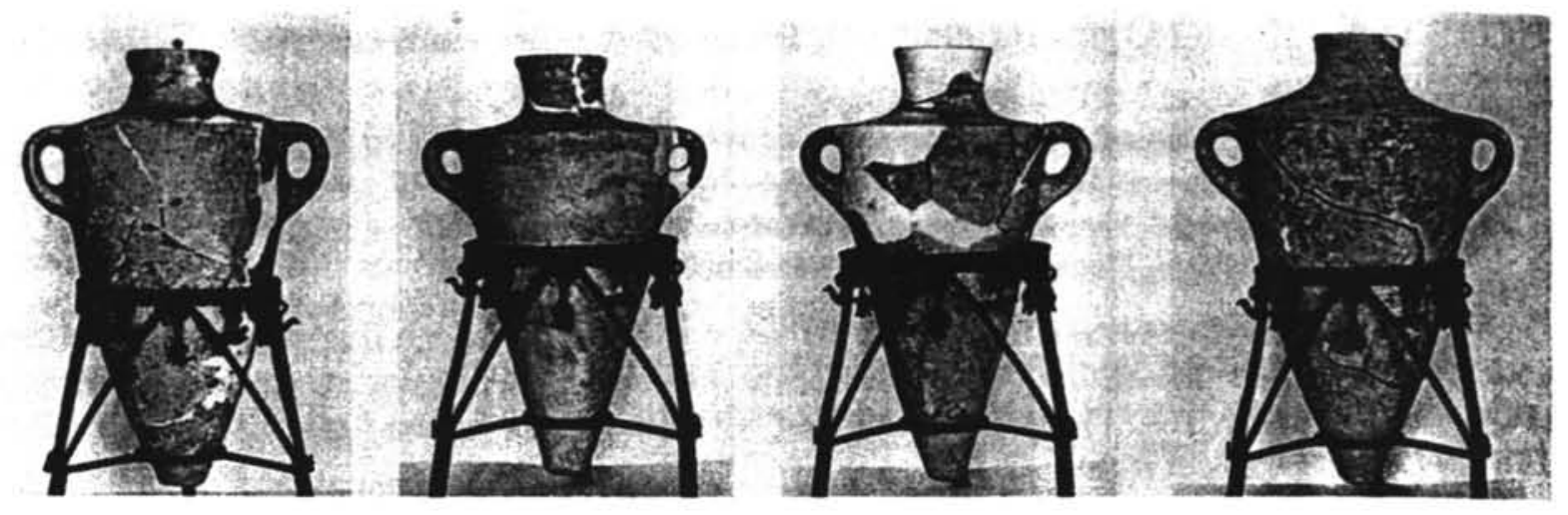

Fig. 6: Ánforas cananeas de Micenas y Menidi.

El recipiente cumple, por tanto, los requisitos necesarios para ser identificado con el $k d^{51}$. Se trata de una vasija con usos olearios y, sobre todo, vinarios. Se halla extendida por el área aproximada de los testimonios lingüísticos en la época del archivo ugarítico. La forma es característica, y se halla abundantemente en Ugarit. Y, como veremos a continuación, podría ser más que apropiada para los usos de la administración ugarítica y el comercio de la época.

\section{TIPOS Y CAPACIDAD DE LAS ÁNFORAS CANANEAS}

Las mediciones de capacidad de las ánforas cananeas no abundan y las diferentes variaciones en el tiempo, y los diferentes modelos coexistentes, añaden dificultades. En Egipto, Meeks (1993,30-33) calculóla capacidad media de un ánfora típica del Reino Nuevo seleccionando ejemplares que él consideró representativos. Halló una capacidad de

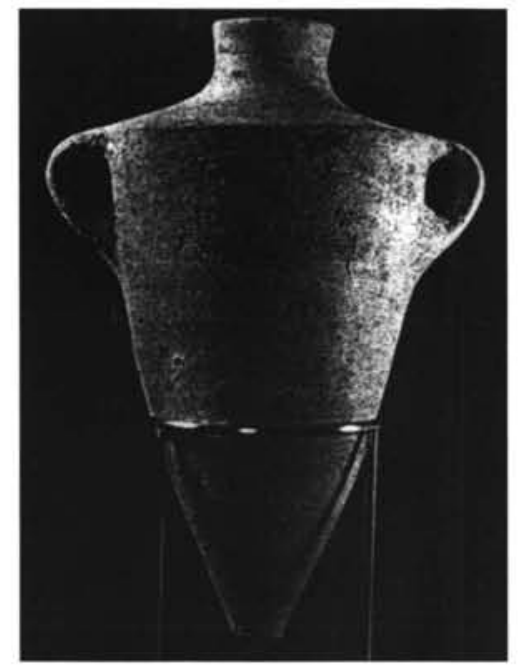

Fig. 7: Ánfora cananea hallada en Micenas.

49. De Pulak 1997: 241, fig. 9.

50. Sobre las ánforas cananeas en Micenas, $c f$. Grace1956: 86 y ss; en Creta, Micenas y Egipto, $c f$. Leonard 1995; Lesko 1995; 1997 ; 6 Meeks 1993: 3-38; sobre Chipre, cf. p. ej., con estudio analítico, Gunneweg - Perlman - Asaro 1987: 168-172, que relacionan un ejemplar chipriota de nuevo con Canaán; también Åström 1991: 149-151. Véase más arriba, en el pasaje dedicado a las etiquetas e inscripciones en ánforas, sobre las inscripciones. Sobre los restos más conocidos de naufragios véase p. ej. las obras de Bass 1967 ó 1986: 269-96; Bass - Pulak - Collon - Weinstein 1989: 1-29; o del mismo Bass 1991: 69-82 y, más ligero, 1987: 693-733. Por último, importante y reciente, Pulak 1997: 233-262.

51. M. Liverani (1979: 1332-1333), de nuevo con notable intuición, ya había propuesto que el $k d$ de los textos administrativos fuera "la 'Canaanite Jar' des archéologues". La suya fue una afirmación al vuelo, por lo que aceptaba igualmente, sin más argumentación, como veíamos, una capacidad de 22-23 litros para la vasija. 
aproximadamente 10 litros, que igualó a la unidad de medida menet ${ }^{52}$. V. Grace, en el trabajo clásico sobre las ánforas cananeas, recogía las medidas y capacidades de diferentes ánforas del área (Grace 1956; $c f$. p. ej. 101 y sig., con información sobre ejemplares recogidos en láminas). Para las más antiguas, de hombros redondeados y con diámetro y altura ligeramente mayores, Grace da cifras superiores a los 20 litros $^{53}$. Pero las cifras de capacidad descienden en los ejemplares típicos posteriores, de hombros angulosos y dimensiones algo menores, rondando los 11 litros en testimonios de el-Amarna, Micenas o Menidi ${ }^{54}$. En la época de mayor extensión de la forma, las ánforas más comunes parecen tener aproximadamente esta capacidad.

Se debe, sin embargo, considerar que las variaciones no se dan sólo en el tiempo. También existen, como es lógico, ejemplares contemporáneos de diferentes tamaños. El pecio de Uluburun (cf. Pulak 1997), que presenta al menos 149 ánforas cananeas, proporciona, por su excavación reciente, interesantes datos. Las ánforas cananeas son identificadas como de tipo "septentrional", procedentes de la costa de la actual Siria o, todo lo más, del norte de Israel. Se distinguen tres tipos de ánforas, cuyas capacidades medias son de 6' 7 , c. 13 y 26 ' 7 litros. El grupo más numeroso es, no el segundo, si no el primero ( $75 \%$ del total). Resulta interesante comprobar el escalonamiento de capacidades (1:2:4) que de nuevo sugiere coincidencias con sistemas métricos. Naturalmente, si quisiéramos llevar esta hipótesis hasta sus últimas consecuencias, deberíamos decidir cuál de las tres capacidades debe ser tomada como la medida patrón. Pero lo cierto es que cualquiera de las tres podría serlo ${ }^{55}$. El tipo intermedio es el más cercano a los otros testimonios citados $\mathrm{y}$, como vamos a ver, parece sobre todo el más cercano al tipo ugarítico más común en Minet el-Beida (si los datos publicados son representativos). En cualquier caso, el hallazgo de Uluburun señala el tamaño preferentemente pequeño de las ánforas del periodo para este tipo de transporte. La preferencia por ejemplares incluso más pequeños que las ánforas de 10-12 litros parece lógico en el contexto hallado, a la luz de la necesidad de amortizar el todavía relativamente caro transporte marítimo comerciando con cantidades pequeñas de productos preciados en envases no muy grandes ${ }^{56}$.

52. En cambio McGovern 1997: 73, hablaba de las ánforas cananeas egipcias como de vasijas de una "usual volumetric capacity of 30 litres", sin citas; en 74 representa dos ánforas cananeas, a escala 1:6, que parecen tener algo menos de $50 \mathrm{~cm}$ de alto. La segunda es casi idéntica a las ánforas halladas en el puerto de Ugarit, que con una altura mayor no contienen ni siquiera la mitad de los 30 litros citados por McGovern, que debe referirse a otros recipientes. Véase más adelante.

53. Un ánfora del ágora de Atenas, de finales del XV a. C., mide $58 \mathrm{~cm}$ de altura y $32 ' 5 \mathrm{~cm}$ de diámetro, para una capacidad de 22' 575 l. Un ejemplar de Argos de la misma época, mide $56 \mathrm{~cm}$ de altura y $31 \mathrm{~cm}$ de diámetro, por lo que la capacidad, con la misma forma, debió ser ligeramente menor. Estas ánforas cananeas, más abombadas, aparecen también en los pecios de mediados del II milenio a. C. Ejemplares panzudos y apuntados debieron convivir, para generalizarse èn el comercio los más aptos al transporte. Desgraciadamente, no existe un estudio más extenso y detallado que permita distinguir con mayor exactitud tipologías y volúmenes por áreas y fechas.

54. Un ánfora de el-Amarna, muy parecida a las ugaríticas, mide $54 \mathrm{~cm}$ de alto. Similares medidas tienen diferentes ánforas de Micenas, de la misma época. Una de ellas, de $55^{\prime} 5 \mathrm{~cm}$ de altura ( $45 \mathrm{~cm}$ hasta los hombros) y $25^{\prime} 3 \mathrm{~cm}$ de diámetro, tiene una capacidad de 11'55 l hasta el cuello (y $365 \mathrm{cc}$ más hasta el borde). Otro ejemplar mide $48 \mathrm{~cm}$ de alto, pero debió ser más alta intacta; tiene $43^{\prime} 5 \mathrm{~cm}$ hasta el hombro, casi como la anterior, y $24^{\prime} 7 \mathrm{~cm}$ de diámetro, por lo que su capacidad debió ser ligeramente menor que la anterior. Otra ánfora se mueve en cifras cercanas a la primera, $54 \mathrm{~cm}$ de alto ( $45 \mathrm{~cm}$ hasta los hombros) y $25^{\prime} 7 \mathrm{~cm}$ de diámetro. La capacidad debió ser por tanto muy parecida. En Menidi, ejemplares del s. XIII a. C. presentan formas muy semejantes a las anteriores. Aunque hay ejemplares con cifras de capacidad sorprendentemente bajas (6' 141 hasta el hombro más 355 cc hasta el borde, para un ánfora de 50' $5 \mathrm{~cm}$ de altura y $24^{\prime} 2 \mathrm{~cm}$ de diámetro; otra parece medir $48 \mathrm{~cm}$ de alto), otras encajan perfectamente con las cifras anteriores (11' 81 hasta el hombro más $375 \mathrm{cc}$ hasta el borde, para un ánfora de $55 \mathrm{~cm}$ de alto, $46 \mathrm{~cm}$ hasta el hombro y $26^{\prime} 8 \mathrm{~cm}$ de diámetro). Más ánforas tienen medidas similares: $53 \mathrm{~cm}$ de alto (44 cm hasta el hombro) y $24^{\prime} 5 \mathrm{~cm}$ de diámetro.

55. Pulak 1997: 240 (con los datos detallados citados) veía en la medida mayor el bath hebreo.

56. P. ej., una parte de las ánforas estaba sólo parcialmente llena de resina de terebinto, Pulak 1997: 240-241. 

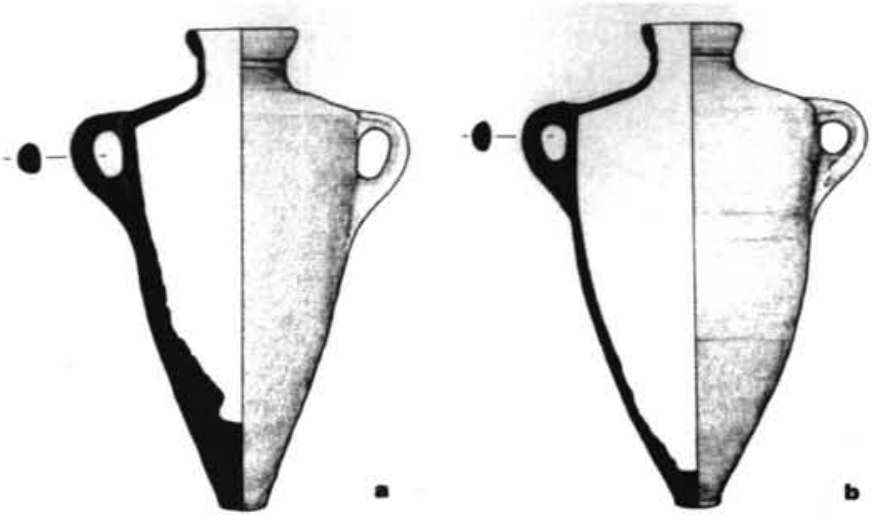

Fig. 8: Ánforas cananeas de Uluburun. La de la izda. tiene una capacidad de 7'8 litros; la de la dcha., tipológicamente muy similar a las ánforas de Minet el-Beida, 13 ’0 litros.

Dentro de la misma ciudad de Ugarit hay abundantes testimonios de ánforas cananeas ${ }^{57}$. Pero los mejores ejemplares son los del hallazgo de la bodega de Minet el-Beida, el puerto ugarítico. Las publicaciones sobre los hallazgos del puerto no dan apenas información cuantificada ${ }^{58}$. De los datos disponibles sobre las vasijas y de los cálculos posibles sobre esos datos ${ }^{59}$ surgen algunas conclusiones, que expusimos en trabajos anteriores ${ }^{60}$ y reconsideraremos aquí.

En aquellos trabajos, con base en cantidades medias y en hipótesis reconstructivas [Fig. 9-1 $1{ }^{61}$ ], se deducía una capacidad tipo para las ánforas de Minet cercana a la cifra media proporcionada por Courtois ${ }^{62} \mathrm{y}$ a la de los ejemplares egeos y levantinos más tardíos de tipo medio. En efecto, estos últimos son casi idénticos

57. Hay fragmentos de ánforas cananeas por toda la ciudad, véase Yon - Lombard - Renisio 1987: p. ej. 40-41, 46-47 (ejemplar con perforación en el fondo), 78, 80, 82 (con inscripción), 83, 100 (foto), 106 ó 108; muchos fragmentos llevan signos incisos, véase también p. ej. Courtois 1978: 278-279. Véase más arriba, en nota al etiquetado de las ánforas.

58. Tan sólo se proporciona la altura del recipiente, $55 \mathrm{~cm}$, y el alzado de uno de los ejemplares. Véase más abajo. Sobre la bodega o almacén de las 80 ánforas, $c f$. Schaeffer 1932: 2-3, lám. III, 3; Schaeffer 1939: 30-32, lám. IX; Schaeffer 1949b: 208-209, fig. 86, lám. 31; Courtois 1979: col. 1285. Más reciente $c f$. Yon 1997: 152-153, que proporciona las medidas del ejemplar RS 3.257 : $52 \mathrm{~cm}$ de alto x 35 de diámetro. Ahora también Marchegay 2001: 19.

59. Partiendo del alzado y de los $55 \mathrm{~cm}$ de altura publicados, se llega a una cifra cercana a los 12-13 litros de capacidad hasta el cuello. Mediante diseño asistido por ordenador, puede generarse un sólido por rotación, cuyo volumen interior total ronda los 141 y medio. De hecho, puede generarse una forma exterior que, si fuera conocido el peso de la vasija, permitiría hallar, además del volumen exterior, la densidad de la cerámica. La sencillez del alzado de partida no permite conocer con exactitud el grosor de la pieza, que en algunas zonas, como el fondo, debió ser mayor que el establecido genéricamente en el cálculo. Además, hay que restar a la cantidad anterior el volumen del cuello. Sólo la parte final de éste contiene, según el cálculo informático, casi un litro, por lo que el ánfora, llena hasta el comienzo del cuello, dando espacio al tapón, pudo contener una cantidad algo superior a los 12 litros. Esa debió ser la capacidad total de ánforas como la presentada por Yon 1997: 152-153, que pudo ser aún menor siguiendo las consideraciones citadas. Todas las cifras son aproximadas, debido al material de partida, y por tanto orientativas. Pero sirven para descartar volúmenes mayores. Agradezco a Luis Julve, de la Universidad de Zaragoza, la realización de la reconstrucción inferior y su desinteresada ayuda para la consecución de los cálculos.

60. Véase sobre todo Zamora 2000: 325 y ss. Véase también nota inicial.

61. Véanse notas anteriores.

62. Referida por el citado Milano 1981: 117, n. 127, sin referencias a publicación. La cifra sería también cercana a la posible capacidad de la karpatu mariota. Véase más arriba. 
en forma y medida a los ugaríticos (compárense las ilustraciones anteriores) ${ }^{63}$, y harían pensar en la prevalencia de un tipo medio de ánfora de entre 10 y 12 litros.
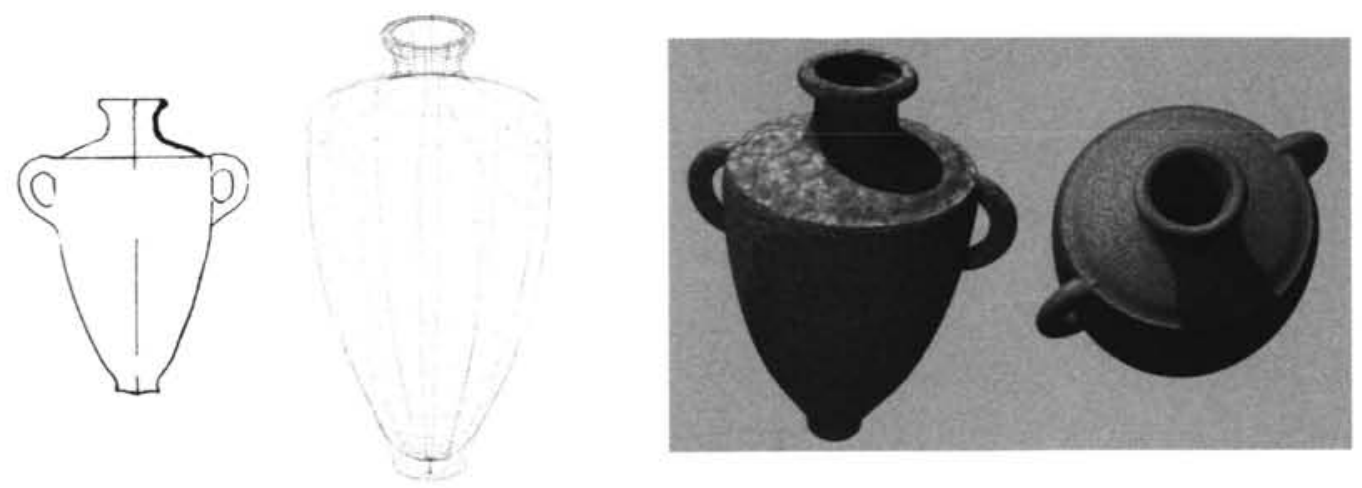

Fig. 9-11: Malla volumétrica y reconstrucción informática aproximada de un ánfora de Minet el-Beida, partiendo del alzado (izquierda) y la altura $(55 \mathrm{~cm})$ publicados. Diferentes escalas.

Debe reconocerse que los datos disponibles no permiten seguridad alguna. De hecho, tanto los datos de partida como las interpretaciones de detalle plantean problemas. Al margen de la exactitud del cálculo reconstructivo, ningún estudio serio puede sostenerse sin conocer la variedad real de las ánforas ugaríticas, incluso de las mismas ánforas de Minet, y sus exactos porcentajes de presencia, convenientemente situados en el tiempo. (Por ejemplo, como ya se apuntaba en ocasiones anteriores, aún aceptando la dudosa igualdad y representatividad de las ánforas de Minet, éstas parecen por su tipología ligeramente anteriores a los últimos testimonios del Bronce Final).

En cualquier caso, los datos permiten pensar que la capacidad de cierto tipo de ánforas cananeas más o menos contemporáneas de los archivos administrativos conservados en Ugarit pudo rondar los 10-12 litros para los ejemplares de talla media. La presencia y relevancia de tal tipo de ánforas debe ser estudiada en profundidad, tanto en Ugarit como en su entorno, antes de llevar más allá otras suposiciones. La sincronía cronológica entre los diversos testimonios ugaríticos, y entre éstos y los datos disponibles del entorno, o es groseramente aproximada o es incierta, lo que obliga a nuevas cautelas. Tampoco los datos publicados permiten ir más allá de la hipótesis. Pero, así las cosas, es igualmente hipotético, e incluso menos sostenido, proponer un dato cercano a los 20, 22 ó 24 litros como capacidad generalizada de las ánforas del Bronce Final más tardío. Debe por tanto formularse con cautela que tal fuera el valor del $k d$, como empezaba a aceptarse ${ }^{64}$, quizás bajo el fuerte condicionamiento de la posterior metrología levantina y mediterránea en general, mejor conocida tanto por los testimonios arqueológicos como por los textos bíblicos y clásicos.

63. Según Schaeffer, las ánforas debían fecharse entre los s. XV-XIV a. C. Por tipología, no sería extraña una fecha ligeramente más reciente (véase más arriba), aunque parece acertada una fecha algo anterior a los ejemplares cananeos más tardíos. La altura de las ánforas ugaríticas del depósito de Minet el-Beida citadas era de 55 y $52 \mathrm{~cm}$. Según el dibujo arqueológico, ésta medida y otras deducibles quedan cerca de las ánforas de Micenas o Menidi de algo más de 11 litros de capacidad. Véase, sobre las ánforas ugaríticas, las obras citadas de Schaeffer 1932: 2-3, lám. III, 3; 1939: 30-32, lám. IX; 1949b: 208-209, fig. 86, lám. 31. Sobre las ánforas del entorno, véase más arriba.

64. En todo caso, para mantener un valor $k d=22$ litros debería separarse, para esta época, el valor del $k d$ de la capacidad habitual de las vasijas, identificándolo sólo con algunas, desde luego no las más abundantes. La identificación $k d$ = ánfora cananea típica ya no se daría en la época final ugarítica. Habría que suponer que el estándar de medida, tras la identificación con un recipiente típico, se fijó mucho tiempo atrás, en una etapa en la que el ánfora cananea tenía una mayor capacidad. Pero la forma pudo fijar su tipología y extenderse con una capacidad menor, y la identificación de recipiente típico y medida extendida en las últimas etapas del Bronce Final es siempre posible. 
A cambio, aun sin poder identificar exactamente cuál de los diferentes tipos de ánfora cananea se correspondió en origen y correspondió al final con el $k d$ citado en los textos de Ugarit, sí parece posible afirmar que la relación del $k d$ con estas vasijas, su identificación, es más que probable.

\section{EL $K D$, ÁNFORA CANANEA}

Asumamos pues tal igualdad. Supongamos que, en un determinado momento del bronce final, la extensión de un tipo de recipiente en gran medida estandarizado dio origen a prácticas de cuenta administrativas que desembocaron en usos metrológicos. Supongamos que tal recipiente fuera un tipo de "ánfora cananea", y que fuera llamada $k d$ entre los semitas noroccidentales. Tal ánfora se extendió y, probablemente, evolucionó, entre el momento inicial de su uso estándar y el momento de los testimonios textuales. El $k d$, en lugares como Ugarit, pudo en consecuencia cambiar o no su valor metrológico, pero la identificación entre alguna clase concreta de la vasija y la forma de cuenta parece mantenerse.

Dicho esto, ¿qué tipo de interpretación podemos darle? ¿Y cómo ayuda esta interpretación a formular una hipótesis más concreta sobre, por ejemplo, el tamaño del ánfora usada como patrón metrológico? Podemos recuperar aquí parte de nuestros discursos anteriores. Es más difícil que, en el momento de fijación o de configuración de un sistema metrológico, las ánforas más grandes constituyeran una medida estándar, por problemas prácticos ${ }^{65}$. Un ánfora romana de 22-25 litros ya exige dos personas para el manejo seguro, y es pesada incluso en vacío. Aunque plantea otras ventajas (sobre todo en épocas de seguridad y buenas condiciones de transporte, de almacenamiento, o de comercio a gran escala, etc.) podría resultar demasiado pesada y voluminosa para algunas actividades en el tiempo que nos ocupa. Un ánfora de unos $10 \mathrm{u} 11$ litros, en cambio, podía ser transportada por una persona [Fig. 12] $]^{66}$, facilitando su uso en contextos "domésticos". También resultaría más práctica para el comercio de mercancías de mínima infraestructura, o para el comercio llevado a cabo en etapas en las que la dedicación de mano de obra a tales actividades era menor que la conocida posteriormente. En intercambios, además, de cierto riesgo, los recipientes pequeños son siempre una ventaja. La rotura de un ánfora media o pequeña no supondría la pérdida de una cantidad excesivamente abundante de producto. El recipiente se adaptaría además perfectamente al transporte de productos caros, los únicos rentables con anterioridad a la generalización de las grandes cargas, en cualquier caso ya presentes. Localmente, como unidad de medida, un $k d$ de 10-11 litros podría haber resultado más útil a una economía levantina del Bronce Final como la ugarítica. De hecho, los textos administrativos atestiguan cifras sin apenas términos que puedan corresponder a divisores y múltiplos ${ }^{67}$.

En definitiva, $k d(k a d d u$ ) podría ser, en la época final del archivo de Ugarit, el nombre ugarítico (y probablemente no sólo ugarítico) dado al "ánfora cananea" o, en sentido restringido, a algún tipo de estas ánforas. Las vasijas eran el típico contenedor de vino y aceite, presente en abundancia en Ugarit. El almacén del puerto de Ugarit que contenía 80 ánforas cananeas perfectamente alineadas podría ser buen ejemplo de una bodega

65. Existen ejemplos orientales de grandes contenedores estandarizados. En Mari existe el našpakum, que, aunque de capacidad igualmente oscura, parece una vasija de muy grande volumen, igualmente estandarizada, $c f$. Powell 1995: 110-111. Sin embargo, ni se hace medida típica ni centro del patrón metrológico.

66. De Leonard 1995: 238. Obsérvese como un ánfora diferente, sin asas y algo mayor, es transportada còlgando de una pértiga por dos personas.

67. Aunque solo sea a modo de ilustración, y no de comparación, todavía en épocas recientes medidas de capacidad semejantes servían para medir, a la vez que almacenar o transportar, cantidades de vino en zonas rurales incluso en la Península Ibérica. Véase en nota inicial el sentido de los "cántaros" o "cántaras" españoles. 


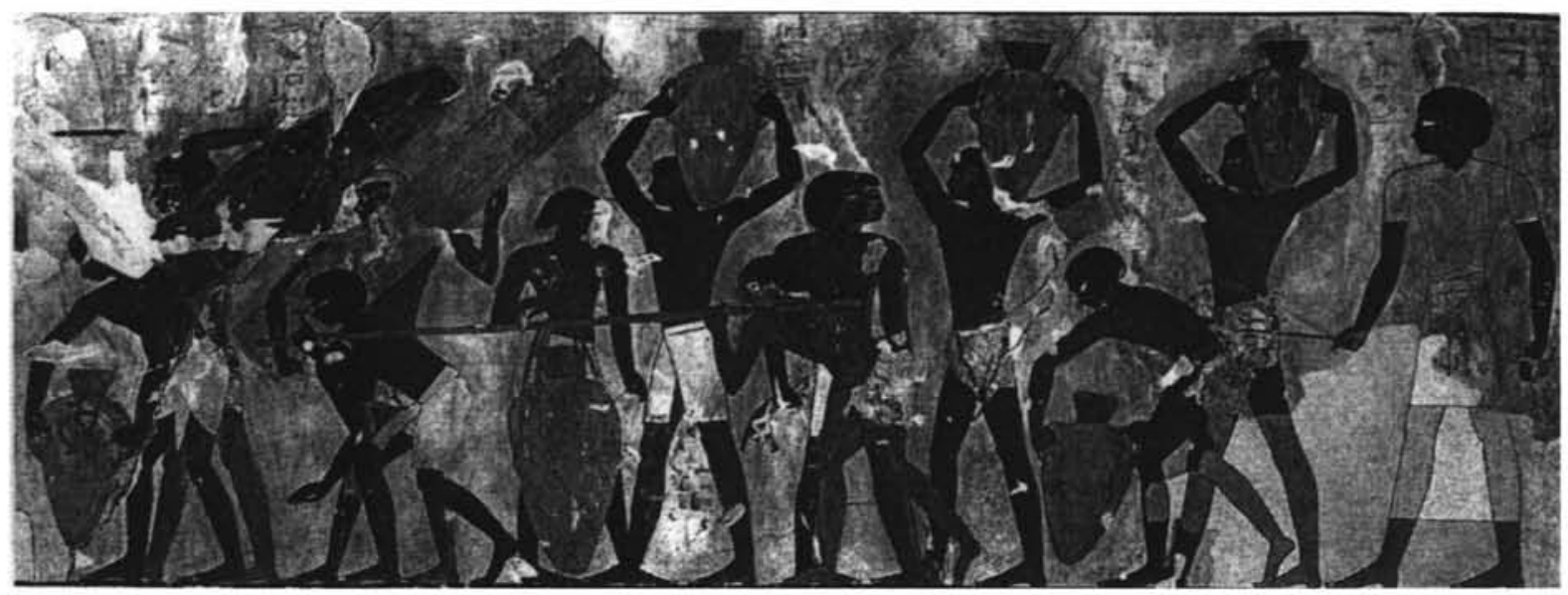

Fig. 12: Ánforas selladas transportadas a hombros. Tumba de Rakhmire, Tebas, Reino Nuevo

o almacén ugarítico. Ello explicaría que la unidad de cuenta básica, la más sencilla y evidente, fuera el propio kaddu, como se atestigua en los textos administrativos y en las etiquetas, donde es usado de forma regular y regulada.

\section{CONCLUSIONES}

Resumiendo de modo diverso: el nombre $k d$ pudo ser la palabra semítica noroccidental que, refiriéndose a vasijas, acabara aplicándose en la segunda mitad del II milenio a. C. a recipientes con la forma característica de las ánforas: boca estrecha, hombros acusados, fondo apuntado y asas. Con la extensión en la edad del bronce final de un tipo característico de ánforas, llamadas por los arqueólogos "ánforas cananeas", tal nombre, ya fuera como genérico ya fuera como término específico, pudo referirlas. De allí, puede proponerse el nacimiento de una unidad de medida, el $k d$ de los textos administrativos ugaríticos, con una capacidad ligada a la capacidad estándar de las ánforas más comunes o útiles, bien en el momento del nacimiento de la unidad, bien en cada momento en que se atestigua. Por estos y otros motivos, no puede fijarse con precisión tal capacidad para un lugar y momento determinado, aunque sí formular hipótesis más generales. Para el momento final de la Edad del Bronce correspondiente al archivo ugarítico, se ha pensado en una medida de en torno a los 20,22 ó 24 litros, como las vigentes posteriormente, aunque se podría igualmente proponer una medida basada en contenedores de 10-11 litros, o poco mayores ${ }^{68}$. Por las salvedades ya expuestas, todas las cifras deben tomarse con cautela. Siempre quedará la duda, además, sobre cuándo y cómo se fijó la unidad de medida y cuál fue desde entonces su verdadera relación con las vasijas realmente extendidas. También sobre la manera exacta en que el control administrativo se servía del $k d$, con un uso metrológico independiente de los contenedores o cuantificando a través del recipiente. Pero el uso continuo y reglado del $k d$ es, en

68. A modo de aproximación, puede servirnos para calcular el posible volumen del vino citado en los textos ugaríticos. P. ej., la corta lista 4.285 proporciona un total de 57 ánforas anotadas a 12 individuos, a una media de 4 ánforas y $3 / 4$ por individuo. Un $k d$ de unos 11 litros arrojaría una cifra total de 627 litros, más de 52 litros por persona. Existen documentos ugaríticos que recogen varios centenares de ánforas y, por tanto, varios miles de litros de vino, véase Zamora 2000: 493. 
cualquier caso, un hecho, y su relación con el tipo o tipos de vasija llamados "ánforas cananeas" nos parece muy probable.

La continuidad del patrón metrológico no es tan clara como la evolución continua de la forma cerámica hacia tipologías características del mundo fenicio y después púnico. De igual modo, la palabra $k d$, aunque no tiene en las inscripciones fenicio-púnicas el protagonismo que poseía en el archivo ugarítico, se conserva y parece ligarse, igualmente, a los contenedores cerámicos, quizá también de tipo anfórico (Amadasi 1990: 17-20) ${ }^{69}$. De nuevo, testimonios epigráficos y arqueológicos próximo-orientales del II milenio a. C. proporcionan un iluminador precedente a los testimonios epigráficos y arqueológicos extendidos por los fenicios, y después por los púnicos, durante el I milenio a. C. a lo largo de todo el mediterráneo. Pero, sobre todo, permiten apreciar, además, el alto grado de sofisticación, regularización e intensidad del comercio y la administración del Levante próximo oriental en la segunda mitad del II milenio a. C., algo que no debe olvidarse al considerar la extensión posterior hacia occidente de las gentes siro-palestinas.

\section{BIBLIOGRAFÍA}

AA. VV. (1992): Diccionario de la Real Academia Española (II vol.), Madrid (21 ed.).

ALONI, A. (1983): "Osservazioni su Gr kádos", Acme 36: 43-49.

AMADASI, M. G. (1987): "Inscrizioni Semitice di Nord-Ouest in contesti Greci e Italici (X-VII sec. A. C.)", DdA 5: 13-27.

- (1990): "Noms de vases en phénicien", Semitica 38, 17-20.

AMIRAN, R. (1969): Ancient Pottery of the Holy Land, Jerusalen.

AMOURETTI, M. C. y BRUN, J.-P. (eds.) (1993): La production du vin et de l'huile en Méditerranée. Oil and Wine production in the Mediterranean area. Actes du symposium internacional. Bulletin de correspondance hellenique. Supplément XXVI. Athénes.

ARNAUD, D. (1967): "Contribution a l'étude de la métrologie syrienne au IIe millénaire”, RA 61: 151-169.

ÅSTRÖM, P. (1991): “Canaanite Jars from Hala Sultan Tekke”, GALE, N. H. (ed.), Bronze Age Trade in the Mediterranean, Jonsered.

- y MASSON, E. (1982): "A silver bowl with canaanite inscription from Hala Sultan Tekké", Report of the Department of Antiquities Cyprus 1982, Nicosia-Cyprus: 72-77.

BASS, G. F. (1967): Cape Gelidonya. A Bronze Age Shipwreck, Philadelphia.

_ (1986): “A Bronze Age Shipwreck at Ulu Burun (Kas): 1984 Campaign”, AJA 90: 269-96.

(1991): "Evidence of Trade from Bronze Age shipwrecks", en GALE, N. H. (ed.), Bronze Age Trade in he Mediterranean, Jonsered: 69-82.

— ; PULAK, C.; COLLON, D. y WEINSTEIN, J. (1989): “The Bronze Age Shipwreck at Ulu Burun: 1986 Campaign", AJA 93: 1-29.

BIROT, M. (ed.) (1960): Archives Royales de Mari (=ARM) 9. Textes administratifs de la salle 5, Paris. BORDREUIL, P. (1985): “KBD: 'Ensemble' dans les textes alphabetiques d'Ougarit”, SEL 2: 89-92.

y PARDEE, D. (1989): La Trouvaille épigraphique de l'Ougarit I: Concordance (RSO $5=$ TEO 1), Paris.

- y PARDEE, D. (1992): "Ugarit. Texts and Literature", en D. N. Freedman (ed.), The Anchor bible Dictionary, vol. 6, New York et al.: 706-721.

69. Amadasi recoge los dos posibles testimonios del $k d$ fenicio-púnico: el de una inscripción del s. VII a. C. hallada en Ialysos (Rodas) y el de la inscripción neopúnica hallada en Galera (España), asignada paleográficamente al s. II a. C. 
BOTTÉRO, J. (1957): Archives Royales de Mari: Textes (=ARMT) 7. Textes économiques et administratifs, Paris.

COHEN, R. y WESTBROOK, R. (2000): Amarna Diplomacy. The beginnings of international relations, Baltimore / London.

COURTOIS, J.-C. (1978): "Corpus céramique de Ras Shamra-Ugarit. Ile. partie. Niveaux historiques d'Ugarit", en SCHAEFFER, C. F. A. et al., Ugaritica VII: 191-376, Paris.

(1979): "Archéologie", SDB 9 (1979): col. 1126-1295.

CUNCHILLOS, J.-L. y VITA, J.-P. (1995): Concordancia de Palabras Ugaríticas en morfología desplegada $(=C P U)$, Madrid / Zaragoza.

—_CERVIGÓN, R.; GALÁN, J.M.; VITA, J.-P. y ZAMORA, J. Á. (1996): Generador de Segmentaciones, Restituciones y Concordancias $(=$ GSRC), Madrid.

; CERVIGÓN, R.; VITA, J.-P.; ZAMORA, J. Á.; SIABRA, J.; CASTRO, A. y LACADENA, A. (2001 a, b): Ugaritic Data Bank. Modules I and II (CD-ROM Macintosh: a) ed. en español; b) English ed.), Madrid.

; CERVIGÓN, R.; VITA, J.-P.; ZAMORA, J. Á.; SIABRA, J.; CASTRO, A. y LACADENA, A. (2002a, b): Ugaritic Data Bank. Modules I and II (CD-ROM Windows: a) ed. en español; b) English ed.), Madrid.

; VITA, J.-P. y ZAMORA, J. Á. (2003): Ugaritic Data Bank. The Texts with english comentaries, Madrid.

DEL OLMO, G. y SANMARTÍN, J. (1996): Diccionario de la Lengua Ugarítica (=DLU), vol. I, Sabadell.

y SANMARTÍN, J. (1996): A Dictionary of the Ugaritic Language in the Alphabetic Tradition, Leiden/ Boston 2003.

DELCOR, M. (1974): "De l'origine de quelques termes relatifs au vin en hébreu biblique et dans les langues voisines", en CAQUOT, A. y COHEN, D., Actes du premier congrès international de linguistique sémitique et chamito-sémitique, Paris 16-19 juillet 1969: 223-233, The Hage / Paris.

DIETRICH, M. y LORETZ, O. (1964-66): “Die soziale Struktur von Alala und Ugarit. Die Berufsbezeichnungen mit der hurritischen Endung - buli”, WO 3: 188-205.

— y LORETZ, O. (1969): "Die soziale Struktur von Alala und Ugarit(V). Die Weingärten des Gebietes von Alala im 15. Jahrhundert", UF 1: 37-64.

— y LORETZ, O. (2000): “Ugaritisch $m(i / a) h d$ 'Hafen' und $m(i / a) b d y$ 'Hafenbewohner'”, UF 32 (2000): 195-200.

— ; LORETZ, O. y SANMARTÍN, J. (1976): Die keilalphabetischen Texte aus Ugarit einschliesslich der keilalphabetischen Texte ausserhalb Ugarits $(=K T U)$, Neukirchen -Vluyn.

— ; LORETZ, O. y SANMARTÍN, J. (1995): Cuneiform Alfabet Texts from Ugarit, Ras Ibn Hani and Other Places $(=C A T=K T U$ II), Münster.

DURAND, J.-M. (1983), Archives Royales de Mari (= ARM) 21. Textes administratifs des salles 134 et 160 du Palais de Mari, Paris.

(1997), Documents épistolaires du palais de Mari, vol. I, Paris.

FINET, A. (1974-77): "Le vin à Mari”, AfO 25: 122-131.

GATES, M.-H. (1988): "Dialogues Between Ancient Near Eastern Texts and the Archaeological Record: Test Cases from Bronze Age Syria", BASOR 270: 63-91.

GRACE, V. R. (1956): "The Canaanite Jar", WEINBERG, S. S. (ed.), The Aegean and the Near East: Studies in honour of Hetty Goldman: 80-109, Locust Valley, New York.

GUNNEWEG, J.; PERLMAN, I. y ASARO, F. (1987): “A Canaanite Jar from Enkomi”, IEJ 37: 168-172

HELCK, W. (1986): "Weinkrug”, HELCK, W. y OTTO, E., Lexikon der Ägyptologie VI: 1182-1186, Wiesbaden. 
HELTZER, M. (1987): “Olive Growing and Olive Oil in Ugarit”, EITAM, D. y HELTZER, M. L., Olive Oil in Antiquity. Israel and neighbouring countries. Conference 1987, Haifa, Haifa 1987 (= EITAM, D. y HELTZER, M. L., Olive Oil in Antiquity. Israel and neighbouring countries, Padova 1996): 106-120. (1989): "Some Questions of the Ugaritic Metrology and its Parallels in Judah, Phoenicia, Mesopotamia and Greece", UF 21: 195-208.

(1990): "Vineyards and Wine in Ugarit (Property and Distribution)", UF 22: 119-135.

(1993): "Olive Oil and Wine Production in Phoenicia and in the Mediterranean Trade", en AMOURETTI,

M. C. y BRUN, J.-P. (eds.) (1993): 49-51.

(1994): "Trade between Egypt and western Asia: New metrological evidence (on E. W. Castle in JESHO XXXV)", en JESHO 37: 318-321.

(1995): $\mathrm{n}^{\circ} 111, N A B U: 96$

(1999): "The Economy of Ugarit", en WATSON, W. G. y WYATT, N. (eds.), Handbook of Ugaritic

Studies (HdO 28), Leiden 1999: 423-454.

HERDNER, A. (1963): Corpus des tablettes en cunéiformes alphabétiques découvertes à Ras Shamra-Ugarit de 1929 à 1939 (=CTA), Paris.

HOFTIJZER, J. (1971): “A note on G 10833: 'išt 'ir and Related Matters”, UF 3: 361-364.

- , JONGELING, K. (1995): Dictionary of the North-West Semtic Inscriptions (= DNWSI), Leiden. HUEHNERGARD, J. (1987): Ugaritic Vocabulary in Sillabic Transcripction, Atlanta.

- (1989): The Akkadian of Ugarit, Atlanta .

KOEHLER, C. G. (1995): "Wine Amphoras in Ancient Greek Trade", MCGOVERN, P. E.; FLEMING, S. y KATZ, S. (eds.): 323-337.

KOEHLER, L. y BAUMGARTNER, W. (1967-90), Hebräisches und aramäisches Lexikon zum alten Testament $(=H A L)$, Leiden.

LEONARD, A. (1995): “'Canaanite Jars' and the Late Bronze Age Aegeo-Levantine Wine Trade”, en MCGOVERN, P. E.; FLEMING, S. y KATZ, S. (eds.) (1995): 233-254.

LESKO, L. H. (1995): "Egyptian Wine Production During the New Kingdom", en MCGOVERN, P. E.; FLEMING, S. y KATZ, S. (eds.), The Origins and Aneient History of Wine: 215-230, Louxembourg. LIPINSKI, E. (1970): "Banquet en l'honneur de Baal. CTA 3 (V AB), A, 4-22", UF 2: 75-88.

LIVERANI, M. (1970): “KBD nei testi amministrativi ugaritici”, $U F$ 2: 89-108.

_ (1972): "Il talento di Ashdod", OA 11: 193-198. (1979): "Histoire", Supplément au Dictionnaire de la Bible (= SDB 9): 1295-1348.

- (1998-99): Le lettere di el-Amarna (2 vol.), Brescia.

MARCHEGAY, S. (2001), “Un plan des fouilles 1929-1935 à Minet el-Beida, le port d'Ougarit”, en YON, M. y ARNAUD, D. (eds.), Etudes Ougaritiques. I. Travaux 1985-1995 (Ras Shamra Ougarit 14): 11-40, Paris.

MCGOVERN, P. E. (1997), "Wine of Egypt's Golden Age: an Archaeochemical perspective”, JEA 83: 69-108.

- FLEMING, S. y KATZ, S. (eds.) (1995): The Origins and Ancient History of Wine, Louxembourg. MASSON, O. (1961): Les inscriptions chypriotes syllabiques, Paris.

MEEKS, D. (1993): “Oléiculture et viticulture dans l'égypte pharaonique”, AMOURETTI, M.C. y BRUN, J.-P. (eds.): 3-38.

MILANO, L. (1981): “Alimentazione e regimi alimentari nella Siria preclassica", DdA 3: 85-121. (1989): "Le razioni alimentari nel Vicino Oriente antico: per un'articolazione storica del sistema", en DOLCE, R. y ZACCAGNINI, C. (eds.), Il pane del Re. Accumulo e distribuzione dei cereali nell'Oriente Antico: 65-100, Bologna. 
MORAN, W. L. (1987): Les lettres d'El-Amarna, Paris. (1992): The Amarna letters, Baltimore / London.

NOUGAYROL, J. (1955): Le Palais Royal d'Ugarit III. Textes accadiens et hurrites des Archives est, ouest et centrales $(=P R U 3)$, Paris.

- (1956): Le Palais Royal d'Ugarit IV. Textes accadiens des Archives sud (Archives internationales) $(=P R U$ 4), Paris.

(1970): Le Palais Royal d'Ugarit VI. Textes en cunéiformes bayloniens des archives du grand palais et du palais sud d'Ugarit (= PRU 6), Paris.

OPPENHEIM, A. L. et al. (1971): The Assyrian Dictionary of the University of Chicago $(=C A D)$, vol. $\mathrm{K}$, Chicago-Glückstadt.

PARISE, N. F. (1984): "Unità ponderali e rapporti di cambio nella Siria del Nord”, en ARCHI, A., (ed.), Circulation of Goods in non-palatial context in the ancient near east: 125-138, Roma.

POO, M.-CH. (1995): Wine and Wine Offering in the Religion of Ancient Egypt, New York.

POWELL, M. A. (1989-90): "Masse und Gewichte", EDZARD, D. O. et al., Reallexikon der Assyriologie (=RlA), vol.7: 457-517, Berlin-Leipzig.

(1995): "Wine and the Vine in Ancient Mesopotamia: The Cuneiform Evidence", en MCGOVERN, P. E.; FLEMING, S. y KATZ, S. (eds.): 97-122.

PULAK, C. (1997): "The Uluburun Shipwreck", en SWINY, S. et al. (eds.), Res Maritimae. Cyprus and the Eastern Mediterranean from Prehistory to Late Antiquity: 233-262, Atlanta.

SANMARTÍN, J. (1990): "El ordo litúrgico KTU 4.14", AuOr 8: 89-99.

SCHAEFFER, C. F. A. (1932): "Les fouilles de Minet-el-Beida et de Ras-Shamra. Troisième campagne (Printemps 1931). Rapport sommaire", Syria 13: 1ss.

- (1933): "Les fouilles de Minet-el-Beida et de Ras-Shamra. Quatrième campagne (Printemps 1932). Rapport sommaire", Syria 14: 93-127.

(1934): "Les fouilles de Ras-Shamra. Cinquième campagne (Printemps 1933). Rapport sommaire", Syria 15: 105-131.

_ (1935): "Les fouilles de Ras Shamra-Ugarit. Sixième campagne (Printemps 1934). Rapport sommaire", Syria 16: 141-176.

- (1939): Ugaritica I. Études relatives aux découvertes de Ras Shamra, Paris.

- (1949a): Ugaritica II. Nouvelles études relatives aux découvertes de Ras Shamra, Paris.

- (1949b): "Corpus céramique de Ras Shamra. Ie. partie”, SCHAEFFER, C. F. A., Ugaritica II: 131-301, Paris.

— et al. (1956): Ugaritica III. Sceaux et cylindres hittltes, épée gravée du cartouche de Mineptah, tablettes chypro-minoennes et autres découvertes nouvelles de Ras Shamra, Paris.

_ et al. (1962): Ugaritica IV. Découvertes des XVIIIe et XIXe campagnes; fondements prehistoriques d'Ugarit et nouveaux sondages; études anthropologiques, poteries grecques et monnaies islamiques de Ras Shamra et environs, Paris.

- et al. (1968): Ugaritica V. Nouveaux textes accadiens, hourrites et ugaritiques des Archives et Bibliotheques privées d'Ugarit. Commentaires des textes historiques (lere p.), Paris.

SCHRADER, C. (ed.) (1986): HERÓDOTO, Historia. Libros III-IV, Madrid.

SIVAN, D. (1984): Gramatical Analysis and Glossary of the Northwest Semitic Vocables in Akkadian Texts of the 15th-13th C. B. C. from Canaan and Syria, AOAT 214, Kevelaer/ Neukirchen-Vluyn.

(1997): A Grammar of the Ugaritic Language (HdO I/28), Leyden / New York / Köln.

STRONACH, D. (1995): "The Imagery of the Wine Bowl: Wine in Assyria in the Early First Nillennium B. C.”, en MCGOVERN, P. E.; FLEMING, S. y KATZ, S. (eds.): 175-195. 
TCHERNIA, A. (1986): Le vin dans l'Italie romaine. Essai d'hitoire économique d'après les amphores, Paris / Rome.

TROPPER, J. (1997): "Beiträge zur ugaritischen Lexicographie", UF 29: 661-663.

— y VITA, J.-P. (1998): "Untersuchungen zu ugaritischen Wirtschaftstexten", UF 30: 686-688.

UNWIN, T. (1991): Wine and the vine. An historical geography of viticulture and the wine trade, London.

VAN SOLDT, W. H. (1989): "Labels from Ugarit", UF 21: 375-388.

— (1991), Studies in the Akkadian of Ugarit, Kevelaer / Neukirchen / Vluyn 1991.

(1996): "Studies in the Topography of Ugarit (1). The Spelling of the Ugaritic Toponyms", UF 28: 653-692.

VARGYAS, P. (1986): "Trade and prices in Ugarit", Oikumene 5: 103-116.

VIROLLEAUD, CH. (1940) "Les villes et les corporations du royaume d'Ugarit", Syria 21: 123-151.

(1957): Le Palais Royal d'Ugarit II (= PRU 2), Paris.

(1965): Le Palais Royal d'Ugarit V (= PRU 5), Paris.

VON SODEN, W. (1965-81): Akkadisches Handwörterbuch (=AHw), Wiesbaden.

WATSON, W. G. E. y WYATT, N. (eds.), Handbook of Ugaritic Studies (Handbuch der Orientalistik I,39), Leiden 1999.

WESSELIUS, J. W. (1980): "Some regularities in the ugaritic administrative texts", $U F$ 12: 448-450.

YON, M. (1997): La cité d'Ougarit sur le Tell de Ras Shamra, Paris.

- y ARNAUD, D. (2001),Etudes Ougaritiques. I. Travaux 1985-1995 (Ras Shamra Ougarit 14), Paris. ; LOMBARD, P. y RENISIO, M. (1987): "L'Organisation de l'habitat", YON, M. (ed.), Ras Shamra Ougarit 3. Le centre de la ville. 38-44e campagnes (1978-1984) (RSO 3): 11-128, Paris.

ZAMORA, J. Á. (1997), Sobre el "Modo de Producción Asiático" en Ugarit, Madrid.

(2000a): La vid y el vino en Ugarit, Madrid.

(2000b): "La misura di superficie šir e il valore non metrologico de $̌ d$ nei testi amministrativi ugaritici", SEL 17: 55-76.

ZETTLER, R. y MILLER, N. F. (1995): "Searching for Wine in the Archaeological Record of Ancient Mesopotamia of the Third and Second Millennia B. C.", MCGOVERN, P. E.; FLEMING, S. y KATZ, S. (eds.): 123-131. 